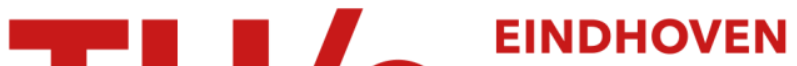 UNIVERSITY OF TECHNOLOGY
}

\section{Estimating panel effects in probabilistic representations of dynamic decision trees using bayesian generalized linear mixture models}

\author{
Citation for published version (APA): \\ Kim, S., Rasouli, S., Timmermans, H., \& Yang, D. (2018). Estimating panel effects in probabilistic \\ representations of dynamic decision trees using bayesian generalized linear mixture models. Transportation \\ Research. Part B: Methodological, 111, 168-184. https://doi.org/10.1016/j.trb.2018.03.010
}

\section{Document license: \\ TAVERNE}

DOI:

10.1016/j.trb.2018.03.010

Document status and date:

Published: 01/05/2018

\section{Document Version:}

Publisher's PDF, also known as Version of Record (includes final page, issue and volume numbers)

\section{Please check the document version of this publication:}

- A submitted manuscript is the version of the article upon submission and before peer-review. There can be important differences between the submitted version and the official published version of record. People interested in the research are advised to contact the author for the final version of the publication, or visit the DOI to the publisher's website.

- The final author version and the galley proof are versions of the publication after peer review.

- The final published version features the final layout of the paper including the volume, issue and page numbers.

Link to publication

\footnotetext{
General rights

- You may freely distribute the URL identifying the publication in the public portal. follow below link for the End User Agreement:

www.tue.nl/taverne

\section{Take down policy}

If you believe that this document breaches copyright please contact us at:

openaccess@tue.nl

providing details and we will investigate your claim.
}

Copyright and moral rights for the publications made accessible in the public portal are retained by the authors and/or other copyright owners and it is a condition of accessing publications that users recognise and abide by the legal requirements associated with these rights.

- Users may download and print one copy of any publication from the public portal for the purpose of private study or research.

- You may not further distribute the material or use it for any profit-making activity or commercial gain

If the publication is distributed under the terms of Article $25 \mathrm{fa}$ of the Dutch Copyright Act, indicated by the "Taverne" license above, please 


\title{
Estimating panel effects in probabilistic representations of dynamic decision trees using bayesian generalized linear mixture models
}

\author{
Seheon Kim ${ }^{\mathrm{a}, *}$, Soora Rasouli ${ }^{\mathrm{a}}$, Harry Timmermans ${ }^{\mathrm{a}, \mathrm{b}}$, Dujuan Yang ${ }^{\mathrm{c}}$ \\ a Eindhoven University of Technology, Urban Planning Group, PO Box 513, Eindhoven 5600MB, The Netherlands \\ ${ }^{\mathrm{b}}$ NUAA, Department of Air Transportation Management, Jiangjun Avenue, Jiangning District, Nanjing 211106, China \\ ${ }^{\mathrm{c}}$ Eindhoven University of Technology, Information Systems in the Built Environment, PO Box 513, Eindhoven 5600MB, The Netherlands
}

\section{A R T I C L E I N F O}

\section{Article history:}

Received 16 November 2017

Revised 16 March 2018

Accepted 19 March 2018

\section{Keywords:}

Panel effects

Random effects

Temporal autocorrelation

Dynamic decision tree

Charging station choice

\begin{abstract}
A B S T R A C T
When collecting panel data, we need to acknowledge that responses do not represent independent measurements. The known apparatus in transportation research offers several opportunities to estimate panel effects for well-known and widely applied models such as hazard and dynamic logit models. However, the transportation research community is not endowed with a rich set of methods to account for panel effects in dynamic probabilistic decision trees, which have been used as a formalism for the representation of decision heuristics. Building on scarce prior work in statistics, we elaborate an approach to estimate panel effects in dynamic probabilistic decision trees with multinomial action states. Given that panel data naturally have a hierarchical structure with repeated measures nested within individuals, we implement a mixed-effects model that simultaneously accounts for population-level effects (fixed effects), between-individual variances (random effects), and within-individual variances (autocorrelations). The approach uses an iterative estimation procedure between CHAID-based probabilistic tree induction and Bayesian generalized linear mixture modeling (GLMM). When extracting the dynamic probabilistic decision trees, it is assumed that the random effects are known, while it is assumed that the fixed effects are known when estimating the Bayesian GLMM. This iterative process continues until convergence is reached. A Monte Carlo technique is used to navigate between aggregate choice probabilities and individual level multinomial choices. We also test the significance of temporal autocorrelation within individuals. The suggested approach is illustrated using charging station choice of users of Plug-in Electric Vehicles (PEV). Results support the potential value of the suggested approach.
\end{abstract}

(c) 2018 Elsevier Ltd. All rights reserved.

\section{Introduction}

Over the last two decades, rule-based models have gained increasing attention as an alternative approach to modeling spatiotemporal choice behavior of daily activity patterns, assuming that choice behavior is driven by heuristic decision rules rather than utility maximization. Rule-based models have often been formulated as a computational process which mimics the decision-making process in complex environments. Decision heuristics reflect the notion that under a particular

\footnotetext{
* Corresponding author.

E-mail addresses: s.kim@tue.nl (S. Kim), s.rasouli@tue.nl (S. Rasouli), h.j.p.timmermans@tue.nl (H. Timmermans), d.yang@tue.nl (D. Yang).
} 
set of conditions an individual with a certain socio-demographic profile, facing a set of spatio-temporal and institutional constraints set by the environment, will activate a particular action state, i.e. choose a particular choice alternative.

Several formalisms may be used to represent the relationship between profile, condition states and actions. For example, IF, THEN, ..., ELSE structures are a logical candidate because they allow specifying the condition set under which an action will follow, while the "ELSE" allows specifying the universe of condition states. However, as this representation is prone to error when dealing with large sets of heuristics demanded in activity-based models of travel demand, decision tree or decision table formalisms have the clear advantage that the exhaustiveness and exclusiveness of decision rules can be easily guaranteed and maintained in complex model systems using predicate logic (Lucardie, 1994). Albatross (Arentze and Timmermans, 2004, 2005; Rasouli et al., 2018) is the best-known activity-based model that is built on such decision trees.

However, the currently increasing interest in developing dynamic models of activity-travel behavior (Arentze and Timmermans, 2009, 2012; Cirillo and Axhausen, 2010; Timmermans et al., 2010; Auld et al., 2011; Shabanpour et al., 2017; Xianyu et al., 2017; Yasmin et al., 2017) and the increasing availability of multi-day, even multi-week GPS data, demand an examination of the issue of panel effects if researchers wish to continue using the formalism of decision trees for developing dynamic models.

It is well-known that any data collection method that requests participants to provide multiple responses to the same type of question violates the common assumption of independent measurements that underlies most statistical methods and choice models. Panel data and stated choice experiments are typical examples. Stated choice experiments involve subjects to choose the alternative they like best from multiple choice sets that systematically vary the attributes and/or decision context variables of interest. Similarly, panel data record multiple behavioral instances of panelists over a longer period of time. Serially correlated choices over time, or autocorrelated choices, and any unobserved variables that have a systematic effect on choice behavior or attitude formation violate the critical assumption of independent measurement.

Although the issue has been recognized for a long time, for example in the context of stated choice experiments, the issue was not immediately remedied, but rather rules of thumbs were applied to correct the problem or a warning was given that the standard errors were inflated. When computing power increased, however, solutions were developed, leading to random effect models for the most commonly used regression and choice models. The random effect allows modeling heterogeneity in cross-sectional data or the effect of repeated measurement in panel/longitudinal data. Consequently, the majority of scholars in transportation research routinely applies random effects models to capture any unobserved preference heterogeneity across individuals and serially correlated choices within individuals. A recent example of a random effects regression models is Rasouli and Timmermans (2014a), who analyzed the effects of multi-tasking on the utility of travel episodes, while Mannering et al., (2016), Anastasopoulos et al., (2017) and Kim et al., (2017) offer examples of random effects hazard models. Charoniti et al., (2017) reported the results of a random parameter regret-minimization model. While the number of applications of the random effects versions of regression, hazard and regret models in transportation research is still relatively limited, applications of mixed (random effects) logit models are very common and have become the standard (e.g., Revelt and Train, 1998; Hensher and Greene, 2003; Vij et al., 2013; Cherchi et al., 2017; Daina et al., 2017).

Nevertheless, travel behavior researchers have not only applied these algebraic choice models, but also used rule-based decision trees such as Chi-squared Automatic Interaction Detector (CHAID) (Arentze et al., 2000; Wets et al., 2000; Rashidi and Mohammadian, 2011; Yang et al., 2013), Classification and Regression Trees (CART) (Rasouli and Timmermans, 2012; Pitombo et al., 2015; Vij and Shankari, 2015). Although the issue of repeated measurement and panel effects applies equally to decision trees, to the best of our knowledge, to date it has not attracted any attention in the transportation research community.

In this article, we propose an approach to estimate panel effects in dynamic probabilistic decision trees with multinomial action states based on CHAID. The essence of CHAID is to successively split the sample into homogeneous subgroups, based on the chi-square criterion, that share similar characteristics and/or conditions. The split can be represented as a tree. Given that panel or longitudinal travel data naturally have a hierarchical structure with repeated measures nested within individuals, we implement a mixed-effects model that simultaneously accounts for population-level effects (fixed effects), between-individual variances (random effects), and within-individual variances (autocorrelations). The approach uses an iterative estimation procedure between CHAID-based probabilistic tree induction and Bayesian generalized linear mixture modeling (GLMM). The suggested approach is illustrated using charging station choice of Plug-in Electric Vehicle (PEV) users.

The remainder of the paper is organized as follows. Section 2 presents the problem of decision tree induction, which hinders to use them for panel data. Section 3 contains the earlier work that attempts to extend tree-based methods to panel data. Section 4 introduces the methodology we develop for estimating panel effects in dynamic probabilistic decision tree with multinomial outcomes. Section 5 illustrates the suggested methodology to PEV users' charging station choice using longitudinal activity-travel data. Section 6 discusses findings from different models and demonstrates their main differences. This is followed by conclusions and a discussion of directions for future research in Section 7.

\section{The problem}

Consider the problem of predicting the probability that individual $i$ will choose choice alternative $j$. A decision tree or table consists of a series of nodes and branches that specify the condition state and personal profile of $i$ that lead (probabilistically) to the choice of $j$. The branches connecting the nodes in the tree (or columns in the table) are exhaustive and 
exclusive. The terminal node of a decision tree (or last row of the decision table) represents the action state, which specifies which action/choice will be triggered when the conditions represented by the connecting branch are satisfied. Traditionally, this is a single action under the deterministic plurality rule, which assigns the modal response at a given terminal node. In case of probabilistic action states, however, the probabilities reflect the heterogeneity in the choice behavior of interest, associated with a decision heuristic. Arentze et al. (2000) and Wets et al. (2000) suggested probabilistic decision trees, which specify the probability that a certain action will be taken, i.e. a particular choice alternative will be chosen.

Basically, tree induction algorithms can be viewed as a way of splitting the observational data into succinct sets of disjunctive decision heuristics that classify the data into homogeneous segments of actions. Originally, these were derived from expert knowledge. Later, several algorithms were suggested to extract the trees or tables from observed activity-travel data. Well-known examples are CHAID-based tree induction (Kass, 1980), which uses the chi-square statistic to build the tree, the C4.5 algorithm (Quinlan, 1993), which is based on the information gain statistic, and CART (Breiman et al., 1984), which is a binary recursive splitting algorithm based on a generalization of the binomial variance, called the Gini index.

The tree induction process itself is deterministic. The stochasticity in simulating choice behavior stems from the probabilistic nature of the decision trees, which means that every instantiation of an action requires a draw from the probabilistic action states, which may result in a different decision outcome. This characteristic is essential for assessing model uncertainty and error propagation in complex model systems (Rasouli and Timmermans, 2013, 2014b).

However, the deterministic induction process implies that the modeling approach at its current level of development and application in transportation research does not include any mechanism for dealing with unobserved preference heterogeneity and autocorrelated errors within individuals. This potential limitation may not be a serious problem for the applications of decision trees in travel behavior modeling that are typically based on cross-sectional travel surveys of a random sample of travelers who report a single day set of trips and activities because any heterogeneity is (largely) reflected in the probability distribution. However, in longitudinal data, repeated observations of a group of travelers cannot be taken into account independently.

When the aim is to develop dynamic decision trees as the driver of dynamic activity-based forecasting models, using longitudinal data, unobserved preference heterogeneity persisting over repeated measurements may lead to correlated choices, and also autocorrelation in choice dynamics is not negligible. Thus, to accommodate these effects, it is necessary to develop a way of extracting the hidden effects of using "panel" data from the decision tree. When searching the literature, we did not find any publication, addressing the issue, let alone suggesting a solution. Some scarce literature in statistics, however, seems promising, but needs elaboration to make it relevant for the probabilistic decision trees embedded in computational process models of activity-travel behavior. In this paper, we suggest the required extension and report experiences with an application of the suggested method based on CHAID-based trees in modeling charging behavior.

\section{Earlier work}

The first attempt to extend tree-based methods to longitudinal data was made by Segal (1992) based on CART. In order to make the method computationally feasible, the algorithm limited the method to have the same number of equally-spaced time intervals for all panelists with commonly used forms of covariance matrices (e.g., independence, compound symmetry, first-order autoregressive). Zhang (1998) extended this approach to multiple binary response variables. It should be noted that these methods share the limitation of not being able to allow time-varying covariates, and the resulting trees cannot be used for future prediction of the same individual.

Some studies in statistics have suggested a way to overcome this limitation, and to deal with longitudinal data by generalizing the linear mixed effects model (LMM) into a CART-based regression tree framework (Hajjem et al., 2011; Sela and Simonoff, 2012). For correlated data (e.g., longitudinal or clustered data) with continuous (e.g., Gaussian) responses, LMMs have been widely used and can be written in matrix form (Laird and Ware, 1982).

$$
\begin{aligned}
& \boldsymbol{y}_{i}=\boldsymbol{X}_{i} \boldsymbol{\beta}+\boldsymbol{Z}_{i} \boldsymbol{b}_{i}+\boldsymbol{\varepsilon}_{i}, \\
& {\left[\begin{array}{l}
\boldsymbol{b}_{i} \\
\boldsymbol{\varepsilon}_{i}
\end{array}\right] \sim N\left(0,\left[\begin{array}{cc}
\boldsymbol{D} & 0 \\
0 & \boldsymbol{R}_{i}
\end{array}\right]\right)}
\end{aligned}
$$

where $\boldsymbol{y}_{i}=\left(y_{i 1}, \ldots, y_{i T_{i}}\right)^{\prime}$ is the $T_{i} \times 1$ vector of continuous responses for the $T_{i}$ observations of a panelist $i$, $\boldsymbol{X}_{i}=$ $\left[x_{i 1}, \ldots, x_{i T_{i}}\right]^{\prime}$ is the $T_{i} \times k$ matrix of fixed effects covariates, $\boldsymbol{\beta}$ is the $k \times 1$ vector of parameters for the fixed effects, $\boldsymbol{Z}_{i}=\left[z_{i 1}, \ldots, z_{i T_{i}}\right]^{\prime}$ is the $T_{i} \times q$ matrix of random effects covariates, $\boldsymbol{b}_{i}=\left(b_{i 1}, \ldots, b_{i q}\right)^{\prime}$ is the $q \times 1$ vector of random effects, and $\boldsymbol{\varepsilon}_{i}=\left(\varepsilon_{i 1}, \ldots, \varepsilon_{i T_{i}}\right)^{\prime}$ is the $T_{i} \times 1$ vector of errors. $\boldsymbol{D}$ and $\boldsymbol{R}_{i}$ are the covariance matrix of $\boldsymbol{b}_{i}$ and $\boldsymbol{\varepsilon}_{i}$, respectively.

The basic idea behind the algorithms proposed by Hajjem et al. (2011) and Sela and Simonoff (2012) is to replace the parametric form of linear fixed effects, $\boldsymbol{X}_{i} \boldsymbol{\beta}$, with the nonparametric form of a nonlinear function $f\left(\boldsymbol{X}_{i}\right)$ from a tree-based model, and is to extract the individual-specific random effects, $\boldsymbol{b}_{i}$, from the outcomes of the regression tree using LMM.

$$
\boldsymbol{y}_{i}=f\left(\boldsymbol{X}_{i}\right)+\boldsymbol{Z}_{i} \boldsymbol{b}_{i}+\boldsymbol{\varepsilon}_{i}
$$

They proposed a two-step iterative expectation-maximization approach to extract the random effects. At the first step, a tree-based model is fitted to $\boldsymbol{y}_{i}-\boldsymbol{Z}_{i} \hat{\boldsymbol{b}}_{i}$ assuming that the random effects are known. As a result, the estimated tree structure, $\hat{f}\left(\boldsymbol{X}_{i}\right)$, is corresponding to the outcomes without random effects. At the second step, the fixed effects are assumed 


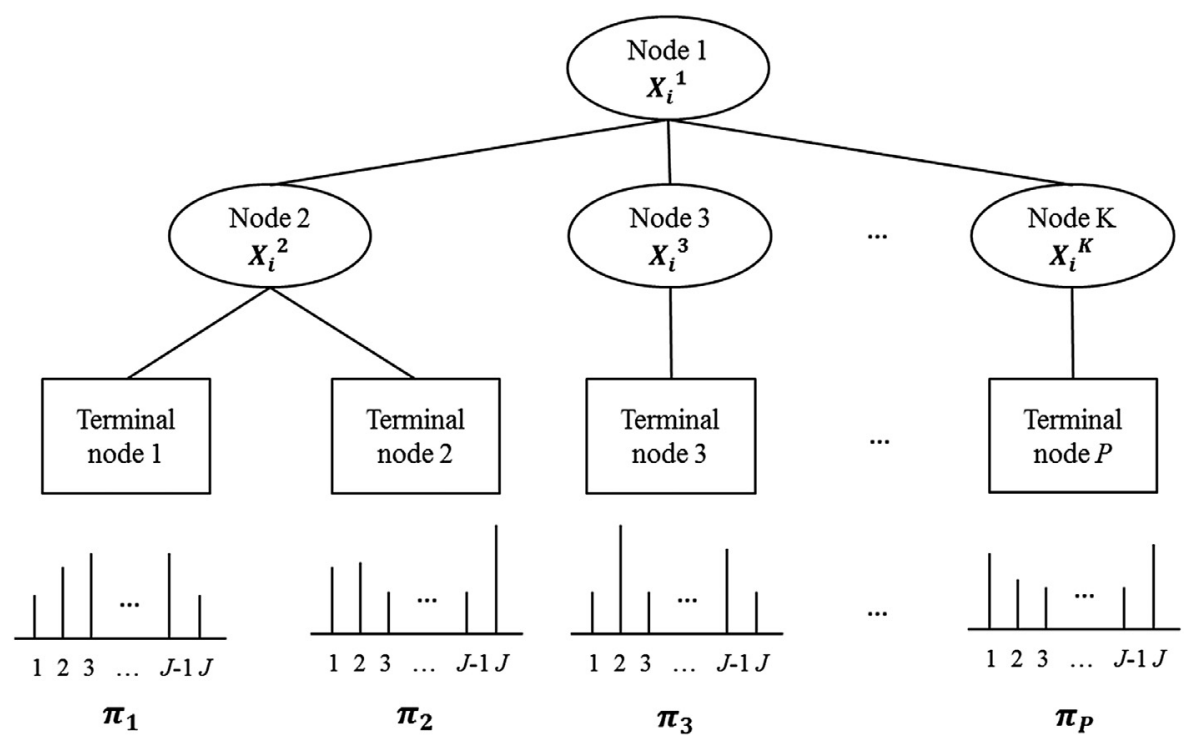

Fig. 1. Graphical representation of CHAID tree.

known, and the LMM is fitted to $\boldsymbol{y}_{i}$ to estimate $\boldsymbol{b}_{i}$. This alternation between the two steps is continued until the change in likelihood (Hajjem et al., 2011) or restricted likelihood (Sela and Simonoff, 2012) between adjacent iterations is less than a specified threshold. Both research teams applied the algorithm to real data and reported that the inclusion of random effects improved the standard tree methods. More recently, to adjust the selection bias of CART, Fu and Simonoff (2015) developed an unbiased version of regression trees for longitudinal data, while Loh and Zheng (2013) proposed an algorithm for the construction regression tree models for longitudinal data, based on the GUIDE approach which avoids selection bias by replacing CART's one-step method of selecting the variable and split set with a two-step method that first selects the variable and then finds the split set for the selected variable. However, given that most choice facets in transport studies are discrete multinomial in nature, developing the dynamic decision tree for non-Gaussian response data is not trivial.

\section{Suggested extension}

In this section, we propose an approach to estimate panel effects in dynamic probabilistic decision trees, based on the CHAID-based tree induction method. However, it should be noted that the proposed method can also be applied in conjunction with any arbitrary classification tree if the tree can be represented by a directed acyclic graph which consists of decision nodes split based on attribute, $\boldsymbol{X}_{i}^{k}$, and terminal nodes with a choice probability distribution across alternatives, $\boldsymbol{\pi}_{p}$, as shown in Fig. 1.

Following Hajjem et al. (2011) and Sela and Simonoff (2012), we apply an iterative approach using a tree-based model to estimate the fixed effects, $f$, and use a Bayesian implementation of generalized linear mixture models (GLMM) to estimate the random effects. The main idea of the extension is to take the random effect (heterogeneity between individuals) into account in the decision tree with categorical (binomial or multinomial) responses. In case of unordered multinomial outcomes, the challenge is to update the outcomes at each iterative step because the outcomes cannot be simply added or subtracted at each iteration. In this section, we describe a method to adjust the CHAID tree for analyzing multinomial outcomes in longitudinal data.

Let $y_{i t}$ be a multinomial random variable taking values $\{1, \ldots J\}$ for the $t$-th observation of individual $i$, where $t=1, \ldots, T_{i}$. Similar to previous work, assuming that the random effects are known, if a CHAID tree is fitted to $y_{i t}$, the tree defines a fixed component, $f_{j}\left(\boldsymbol{X}_{i}\right)$, where $\boldsymbol{X}_{i}$ is the $T_{i} \times k$ matrix of fixed effects covariates. In other words, the estimated fixed component $\hat{f}_{j}\left(\boldsymbol{X}_{i}\right)$ is a complete set of decision rules generated by CHAID satisfying given attributes, which partitions the covariate spaces and indicates the terminal node to which the observations belong. Then, the probabilistic action-assignment rule may come into operation.

$$
\pi_{i j t}^{C H A I D} \mid p=\operatorname{Pr}\left(y_{i t}=j \mid p, \delta_{i j t}\right)=\frac{\delta_{i j t} n_{j p}}{\sum_{j^{\prime}=1}^{J} \delta_{i j^{\prime} t} n_{j^{\prime} p}}, p=1, \ldots, P,
$$

where $\pi_{i j t}^{C H A I D}$ denotes the conditional choice probability of alternative $j$ as seen by individual $i$ at occasion $t, n_{j p}$ is the number of observations at terminal node $p$ with observed response $j$, and $\delta_{i j t}$ is a binary variable indicating the availability of $j$ at occasion $t$.

Once the fixed effects are known from the tree, we fit the GLMM to capture the random effect. Considering the unordered polytomous outcomes we have, an appropriate link function for the GLMM is the baseline-category logit model 
(Agresti, 2013), which is simultaneously parameterized as the log odds over an arbitrary baseline category J. Thus, pairing each response category with a baseline category, $J-1$ non-redundant logits can be written as given below.

$$
\begin{aligned}
& \eta_{i j}=\log \frac{\boldsymbol{\pi}_{\boldsymbol{i j}}}{\boldsymbol{\pi}_{\boldsymbol{i}}}=\hat{f}_{j}\left(\boldsymbol{X}_{i}\right)+Z_{i} \boldsymbol{b}_{i j}, j=1, \ldots, J-1, \\
& \boldsymbol{b}_{i j} \sim N(\mathbf{0}, \boldsymbol{D}),
\end{aligned}
$$

where $\boldsymbol{\eta}_{i j}=\left(\eta_{i j 1}, \ldots, \eta_{i j T_{i}}\right)^{\prime}$ and $\pi_{i j}=\left(\pi_{i j 1}, \ldots, \pi_{i j T_{i}}\right)^{\prime}$ is the $T_{i} \times 1$ vector of linear predictors and response probabilities, respectively, associated with alternative $j$ for individual $i$, hence $\sum_{j=1}^{J} \pi_{i j t}=1 . Z_{i}=\left[z_{i 1}, \ldots, z_{i T_{i}}\right]^{\prime}$ is the $T_{i} \times q$ matrix of random effects covariates, and $\boldsymbol{b}_{i j}=\left(b_{i j 1}, \ldots, b_{i j q}\right)^{\prime}$ is the $q \times 1$ unknown vector of random effects associated with alternative $j$ for individual $i$ with zero mean and covariance matrix $\boldsymbol{D}$.

$\boldsymbol{D}$ is the block diagonal covariance matrix of $\boldsymbol{b}_{i j}$ with diagonal blocks $\boldsymbol{V}_{b_{i j s}} \otimes \boldsymbol{A}_{b_{i j s}}$. Here $\otimes$ denotes Kronecker product and $\boldsymbol{V}_{b_{i j s}}$ is the $(J-1) \times(J-1)$ covariance matrix of $s$-th random effect to be estimated.

$$
\begin{aligned}
& \boldsymbol{D}=\oplus_{s=1}^{q} \boldsymbol{V}_{b_{i j s}} \otimes \boldsymbol{A}_{b_{i j s}}=\left[\begin{array}{cccc}
\boldsymbol{V}_{b_{i j 1}} \otimes \boldsymbol{A}_{b_{i j 1}} & 0 & \ldots & 0 \\
0 & \boldsymbol{V}_{b_{i j 2}} \otimes \boldsymbol{A}_{b_{i j 2}} & \ldots & 0 \\
\vdots & \vdots & \ddots & \vdots \\
0 & 0 & \ldots & \boldsymbol{V}_{b_{i j q}} \otimes \boldsymbol{A}_{b_{i j q}}
\end{array}\right] \\
& \boldsymbol{V}_{b_{i j s}}=\left[\begin{array}{cccc}
\sigma_{b_{i 1 s}}^{2} & \sigma_{b_{i 1 s} b_{i 2 s}} & \ldots & \sigma_{b_{i 1 s} b_{i j-1 s}} \\
\sigma_{b_{i 2 s} b_{i 1 s}} & \sigma_{b_{i 2 s}}^{2} & \ldots & \sigma_{b_{i 2 s} b_{i j-1 s}} \\
\vdots & \vdots & \ddots & \vdots \\
\sigma_{b_{i j-1 s} b_{i 1 s}} & \sigma_{b_{i j-1 s} b_{i 2 s}} & \cdots & \sigma_{b_{i j-1 s}}^{2}
\end{array}\right]
\end{aligned}
$$

$\boldsymbol{A}_{b_{i j s}}$ is the $(J-1) \times(J-1)$ known structured matrix that may have various forms (e.g., unstructured, First-order autoregressive (AR-1), Toeplitz, Compound symmetry, Variance Components, etc.) which defines the covariance structure of $\boldsymbol{V}_{b_{i j j}}$. In this study, the Variance Components structure is chosen which is the simplest assuming no correlation between alternatives (i.e., $\boldsymbol{A}_{b_{i j s}}=\boldsymbol{I}_{J-1}$ ), and results in the $q(J-1) \times q(J-1)$ block diagonal covariance matrix $\boldsymbol{D}$.

$$
\boldsymbol{D}=\oplus_{s=1}^{q} \boldsymbol{V}_{b_{i j s}} \otimes \boldsymbol{I}_{J-1}=\left[\begin{array}{ccccc}
\boldsymbol{V}_{b_{i j 1}} \otimes \boldsymbol{I}_{J-1} & 0 & \ldots & 0 \\
0 & \boldsymbol{V}_{b_{i j 2}} \otimes \boldsymbol{I}_{J-1} & \ldots & 0 \\
\vdots & \vdots & \ddots & \vdots \\
0 & 0 & \ldots & \boldsymbol{V}_{b_{i j q}} \otimes \boldsymbol{I}_{J-1}
\end{array}\right]
$$

Then $J-1$ non-redundant logits determine the log-odds of other pairs of response categories. For example, in case of non-baseline response categories $\mathrm{A}$ and $\mathrm{B}$,

$$
\log \frac{\pi_{i B}}{\pi_{i A}}=\eta_{i B}-\eta_{i A}=\log \frac{\pi_{i B}}{\pi_{i J}}-\log \frac{\pi_{i A}}{\pi_{i J}} .
$$

Often traditional GLMM suffer from modeling non-Gaussian response variables because the likelihood cannot be obtained in closed form. As an alternative, there has been a growing interest in the development of Bayesian approaches to deal with longitudinal data using the Markov-Chain Monte-Carlo (MCMC) estimation method (Chib, 2008). This method relies on the idea of hierarchical prior modeling, which allows modeling the heterogeneity in individual-specific coefficients and the distributions of errors (Lindley and Smith, 1972). We used R package MCMCglmm (Hadfield, 2010). Based on the use of Bayesian inference, MCMCglmm simulates the posterior distribution of fixed effects and random effects based on both the data and the uninformative prior distributions (normal distribution for fixed effects and inverse-Wishart distribution for random effects, respectively). It is known that the uninformative prior distribution has virtually no effect on the posterior if the data are large enough.

When the GLMM is fitted, the response probabilities without random effects can be written as,

$$
\begin{aligned}
& \pi_{i j t}^{M C M C}=\frac{\exp \left(\hat{\eta}_{i j t}-z_{i j t} \hat{\boldsymbol{b}}_{\boldsymbol{i j}}\right)}{1+\sum_{j^{\prime}=1}^{J-1} \exp \left(\hat{\eta}_{i j^{\prime} t}-z_{i j^{\prime} t} \hat{\boldsymbol{b}}_{\boldsymbol{i} \mathbf{j}^{\prime}}\right)}, \quad j=1, \ldots, J-1, \\
& \pi_{i j t}^{M C M C}=\frac{1}{1+\sum_{j^{\prime}=1}^{J-1} \exp \left(\hat{\eta}_{i j^{\prime} t}-z_{i j^{\prime} t} \hat{\boldsymbol{b}}_{\boldsymbol{i} \mathbf{j}^{\prime}}\right)}, j=J .
\end{aligned}
$$
tion.

Finally, the response can be updated using the Monte Carlo technique to draw a decision from the probability distribu-

$$
y_{i t}^{*}=\operatorname{Monte} \operatorname{Carlo}\left(\hat{\pi}_{i j t}^{M C M C}\right)
$$


Table 1

Summary statistics of the data.

\begin{tabular}{ll}
\hline Time span & $1 / 27 / 2017-4 / 28 / 2017$ \\
Total number of users & 73 \\
Total number of charging questions sent & 13,163 \\
Number of charging occasions per person* & minimum $=2,1$ st quartile $=98.3$, median $=166.5,3$ rd quartile $=257.5$, maximum $=593$ \\
Distribution of observed types of charging stations & 1) no charging: 8262 observations \\
& 2) private-charging station: 3213 observations \\
& 3) public-charging station: 711 observations \\
& 4) semi-public charging station: 236 observations \\
& 5) fast charging station: 915 observations
\end{tabular}

Note: In this study, charging occasion refers to the situation when PEV user can charge (i.e., every car trip end). Thus "no charging occasion" is taken into consideration, and was set to the baseline response category.

It should be noted that the updated response, $y_{i t}^{*}$, is a result of taking random effects out and is applied to fit the CHAID probabilistic decision tree again. In other words, it is the effort to minimize the between-individual variance in longitudinal data used for training the tree classifiers. This procedure iterates until convergence, which is measured by changes in the deviance information criterion (DIC). DIC is a Bayesian metric for model selection of hierarchical models, analogous to Akaike Information Criterion (AIC) for non-hierarchical models as the models with smaller values are preferred (Spiegelhalter et al., 2002). The proposed algorithm is written in $R$ ( $R$ Core Team, 2015) and is available from the authors upon request. In summary, the proposed algorithm can be listed as follows:

Step 0 Set the estimated random effects, $\hat{\boldsymbol{b}}_{i j}=0, \hat{\boldsymbol{D}}=\boldsymbol{I}_{q(J-1)}$, and the number of iteration $n=0$

Step 1 Fit a CHAID-based tree to $y_{i t}$, if $n=0$, otherwise to $y_{i t}^{*}$.

Set $n=n+1$ and extract the response probabilities, $\hat{\pi}_{i j t}^{\text {CHAID }}$, from the estimated CHAID tree using Eq. (3). Extract a set of decision rules to be used in Step 2 as a fixed component, $\hat{f}_{j}\left(\boldsymbol{X}_{i}\right)$.

Step 2 Fit Eq. (4) using Markov-Chain Monte-Carlo (MCMC) GLMM

Extract $\hat{\boldsymbol{b}}_{i j}$ from the estimated MCMC GLMM. Update a response from the probabilities, $\hat{\pi}_{i j t}^{M C M C}$, using Eqs. (9) and (10) and set it to $y_{i t}^{*}$ using Eq. (11).

Step 3 Repeat step 1 and step 2 until convergence, measured by $\Delta$ DIC.

\section{Illustration}

\subsection{Charging station choice data}

To illustrate the suggested method for deriving dynamic (or longitudinal) decision trees with random effects that account for the panel data structure, we collected longitudinal data on charging behavior of electric car users. A smartphone-based prompted-recall survey constitutes the basis for the illustration. Smartphone app Sesamo was used to record plug-in electric vehicle (PEV) users' daily spatio-temporal activity-travel patterns. The survey was administered among 100 PEV users in the Netherlands, who downloaded and activated the app, over a period of 3 months (from January 27, 2017 to April 28, 2017). It resulted in observations for 4438 person-days and 23,998 person-trips of 73 users who activated the app at least fourteen days consecutively.

The app automatically tracks travelers and records their spatio-temporal activity-travel patterns, such as trip origins/destinations and departure/arrival time, using available sensors in the smartphone (GPS, Accelerometer, and Wi-Fi), and infers activity type(s) and transport mode(s). Compared to state of the art imputation methods (e.g. Feng and Timmermans, 2013, 2015; Xiao et al., 2016) the imputation is relatively simple. To compensate for the relative lack of accuracy, travelers are frequently asked to confirm and if needed provide additional information about transport modes, locations and activities. The user provided information is then used in combination with the GPS information to better infer transport modes, activity types and locations as the app learns from multi-week traces. Details about the method can be found in Geurs et al. (2015).

The application allows not only tracking trajectories but also asking respondents to provide answers to a set of questions. We programmed the app such as to prompt respondents to confirm the automatically generated travel diary and correct it when wrong at the end of each day. In addition, they were requested to answer questions about their charging decisions, if any, at every car trip end. To reduce the amount of memory recall bias, we felt it was important to ask the charging questions at the end of each trip.

For the illustration, we focus on the decision tree dealing with charging station choice. This decision tree involves a multinomial response from four different types of charging stations and the option of 'No charging'. The alternatives include: 1) no charging, 2) private-charging station, 3) public-charging station, 4) semi-public charging station, and 5) fast charging station. Each PEV user is considered as a cluster in the terminology of GLMM. The data are unbalanced in the sense that the number of responses varies across clusters, and are imbalanced in that the number of observations across the response categories is not equally distributed. Table 1 summarizes the descriptive statistics of the data used in this study. 
Table 2

List of variables.

\begin{tabular}{|c|c|c|}
\hline Variable & & Description \\
\hline \multicolumn{3}{|c|}{ Socio-demographic variable (individual-level) } \\
\hline S1 & Availability of private parking place & $\begin{array}{l}\text { 1: PEV user has an own driveway or garage for parking } \\
0 \text { : PEV user does not have a private parking place }\end{array}$ \\
\hline S2 & Availability of private charging station & $\begin{array}{l}0 \text { : PEV user has own charging point at home, especially for PEV } \\
1 \text { : PEV user can charge a PEV with the aid of a standard AC outlet } \\
\text { at home (Level } 1 \text { charging) } \\
\text { 2: PEV user cannot charge at home }\end{array}$ \\
\hline S3 & $\begin{array}{l}\text { Availability of charging station at } \\
\text { workplace }\end{array}$ & $\begin{array}{l}\text { 0: PEV user can charge a PEV at his/her workplace, especially for } \\
\text { PEV } \\
\text { 1: PEV user can charge a PEV at his/her workplace with the aid of } \\
\text { a standard AC outlet (Level } 1 \text { charging) } \\
\text { 2: PEV user cannot at his/her workplace }\end{array}$ \\
\hline S4 & Pay for charging at workplace & $\begin{array}{l}\text { 0: PEV user has to pay for charging at his/her workplace } \\
1: \text { PEV user does not have to pay for charging at his/her workplace } \\
\text { 2: PEV user does not charge at his/her workplace }\end{array}$ \\
\hline S5 & Gender & 1: PEV user is male, 0 : PEV user is female \\
\hline S6 & Age of PEV user in quintiles & $0:[27,44], 1:(44,48], 2:(48,51], 3:(51,58], 4:(58,76]$ \\
\hline S7 & Education level & $\begin{array}{l}\text { 0: Elementary School, 1: Lower vocational education 2: Lower } \\
\text { general education, } 3 \text { : Medium level general education } 4 \text { : Medium } \\
\text { level vocational education, 5: Higher level vocational education, } \\
6: \text { University, } 7 \text { : otherwise }\end{array}$ \\
\hline S8 & $\begin{array}{l}\text { Work status of PEV user measured by } \\
\text { number of working hours }\end{array}$ & 0: More than $30 \mathrm{~h}, 1: 12-30 \mathrm{~h}, 2$ : Less than $12 \mathrm{~h}, 3$ : Does not work \\
\hline S9 & Personal annual income (in euros) & $\begin{array}{l}0: 0,1:(0,7500], 2:(7500-15,000], 3:(15,000-22,500], 4: \\
(22,500-30,000], 5:(30,000-50,000], 6:>50,000\end{array}$ \\
\hline S10 & Number of vehicles in the household & $0: 1,1: 2,2:(2,3], 3:(3,6]$ \\
\hline S11 & Number of household members & $0: 1$ (single household), $1: 2,2:(2,4], 3:(4,5], 4:(5,7]$ \\
\hline \multicolumn{3}{|c|}{ Time-varying travel-related variable (observation-level) } \\
\hline $\mathrm{T} 1$ & PEV type for the charging occasion & $\begin{array}{l}\text { 0: if Battery Electric Vehicle (BEV), 1: Plug-in Hybrid Electric } \\
\text { Vehicle (PHEV) }\end{array}$ \\
\hline $\mathrm{T} 2$ & $\begin{array}{l}\text { Travel time of a trip to the location of } \\
\text { charging occasion (in minutes) }\end{array}$ & $\begin{array}{l}\text { 0: [1,6.10], 1: (6.10,11.23], 2: }(11.23,20.67], 3:(20.67,37.17] 4: \\
(37.17,228.33]\end{array}$ \\
\hline T3 & $\begin{array}{l}\text { Average travel speed of a trip to charging } \\
\text { occasion (in } \mathrm{km} / \mathrm{h} \text { ) }\end{array}$ & $0:[0,7.2], 1:(7.2,10.1], 2:(10.1,13.9], 3:(13.9,19.4], 4:(19.4,161]$ \\
\hline $\mathrm{T} 4$ & $\begin{array}{l}\text { Travel distance of a previous trip to } \\
\text { charging occasion (in } \mathrm{km} \text { ) }\end{array}$ & $0: 0,1:(0,1.62], 2:(1.62,4.98], 3:(4.98,20.45], 4:>20.45$ \\
\hline T5 & $\begin{array}{l}\text { Travel distance of a trip to charging } \\
\text { occasion (in } \mathrm{km} \text { ) }\end{array}$ & $0:[0,2.30], 1:(2.30,5.13], 2:(5.13,13.14] 3:(13.14,34.03], 4:>34.03$ \\
\hline T6 & $\begin{array}{l}\text { Travel distance of a next trip to charging } \\
\text { occasion (in } \mathrm{km} \text { ) }\end{array}$ & $0: 0,1:(0,1.59], 2:(1.59,4.64], 3:(4.64,17.24], 4:>17.24$ \\
\hline $\mathrm{T} 7$ & $\begin{array}{l}\text { Transport mode used for a previous trip to } \\
\text { charging occasion }\end{array}$ & $\begin{array}{l}\text { 0: Auto, 1: Train, 2:Bus, 3: Bike, 4: Walk, 5: Metro, 6: Tram, 7: } \\
\text { Taxi, 8: Other, 9: First trip }\end{array}$ \\
\hline T8 & $\begin{array}{l}\text { Transport mode used for a next trip to } \\
\text { charging occasion }\end{array}$ & $\begin{array}{l}\text { 0: Auto, 1: Train, 2:Bus, 3: Bike, 4: Walk, 5: Metro, 6: Tram, 7: } \\
\text { Taxi, 8: Other, 9: Last trip }\end{array}$ \\
\hline T9 & $\begin{array}{l}\text { Main purpose of a previous trip to } \\
\text { charging occasion }\end{array}$ & $\begin{array}{l}\text { 0: Only for charging, } 1 \text { : Work or school activity, } 2 \text { : In-home activity } \\
\text { 3: Grocery shopping, 4: Non-grocery shopping, 5: Bring or get } \\
\text { persons or goods, 6: Service or private business, 7: Social activity, } \\
\text { 8: Leisure activity, 9: Waiting, 10: Other activities, 11: Unidentified }\end{array}$ \\
\hline T10 & Main purpose of a trip to charging occasion & Same as T9 \\
\hline T11 & $\begin{array}{l}\text { Main purpose of a next trip to charging } \\
\text { occasion }\end{array}$ & Same as T9 \\
\hline $\mathrm{T} 12$ & $\begin{array}{l}\text { Total stay percentage at previous location } \\
\text { (in percent) }\end{array}$ & $0: 0,1:(0,0.6], 2:(0.6,22.5], 3:(22.5,67.6], 4:(67.6,92.6]$ \\
\hline T13 & $\begin{array}{l}\text { Total stay percentage at current location } \\
\text { for charging occasion (in percent) }\end{array}$ & $0: 0,1:(0,0.6], 2:(0.6,23], 3:(23,67.6], 4:(67.6,92.6]$ \\
\hline T14 & $\begin{array}{l}\text { Distance from home location to current } \\
\text { location (in } \mathrm{km} \text { ) }\end{array}$ & $0:[0,1.86], 1:(1.86,4.82], 2:(4.82,14.04], 3:(14.04,37.34], 4:>37.34$ \\
\hline T15 & $\begin{array}{l}\text { State-of-battery before charging occasion } \\
\text { (in percent) }\end{array}$ & 0: Low $[0,33], 1:$ Medium $(33,66]$ 3: High $(66,100]$ \\
\hline
\end{tabular}

Two broad sets of variables were considered: socio-demographics and time-varying travel-related variables, as shown in Table 2. To apply the CHAID tree induction method, all continuous predictors were categorized in quantiles, based on the distribution of the data. 
Table 3

Model specifications.

\begin{tabular}{llll}
\hline Model & Fixed-effects component & Random-effects component & Auto-correlation \\
\hline 1 & - & - & - \\
2 & Node Indicator * CHAID outcome & Random intercept & - \\
3 & Node Indicator : CHAID outcome & Random intercept & - \\
4 & Node Indicator * CHAID outcome & Random intercept & AR-1 \\
5 & Node Indicator : CHAID outcome & Random intercept & AR-1 \\
\hline
\end{tabular}

Note: 1 . Model 1 is a null model which is the standard CHAID.

2. $A * B$ indicates main effects and their interaction $(A+B+A \times B)$, while $A: B$ indicates an interaction term without main effects $(A \times B)$.

\subsection{Simulation design}

The proposed algorithm is applied to the following specifications of MCMC GLMM.

1. The model with/without random effects

2. The model with different specifications of the fixed effects

a. Terminal node indicator * CHAID outcome ( 2 main effects +1 interaction effect)

b. Terminal node indicator: CHAID outcome (only interaction effect)

3. The model with/without autocorrelation within individual.

First and foremost, the models with and without random effects are compared. To consider the unobserved heterogeneity between individuals, a random individual-specific intercept is introduced (i.e., $\boldsymbol{b}_{i j}=b_{i j 1}$ ), which is referred to as the random intercept model. In other words, it is assumed that the heterogeneity between individuals across repeated measures only shifts upward or downward by an individual-specific fixed amount. For the random intercept model, $\boldsymbol{Z}_{\boldsymbol{i}}$ is the $T_{i} \times 1$ vector of ones. Secondly, different specifications of fixed effects are considered. By taking the interaction between the CHAID outcome and the terminal node, the relationship between the CHAID outcome and the unique probability distribution is tested. Thirdly, the models with and without autocorrelation within individuals across repeated measures are considered. While the occurrence of autocorrelation, or serial correlation, can be evaluated on the covariance structure of errors, $\boldsymbol{R}_{i}$, in LMM as in Eq. (1), it is not the case for GLMM. Rather, we introduce a lagged dependent variable into the model (Kitamura, 2008; Wooldridge, 2010; Chatterjee, 2011), which results in the following equation.

$$
\eta_{i j t}=\hat{f}_{j}\left(x_{i t}\right)+\sum_{l=1}^{t-1} y_{i j t-l} \beta_{j l}+z_{i t} \boldsymbol{b}_{i j}, j=1, \ldots, J-1, t=1, \ldots, T_{i}
$$

where, $y_{i j t-l}$ denotes the choice made at $l$ previous state associated with current choice $j$, and $\beta_{j l}$ is the effect of the past choice $l$ time period ago on the current choice. We postulate a first-order autoregressive (AR-1), most common form of autocorrelation, thus use $y_{i j t-1} \beta_{j 1}$ for the second term on the right hand side of Eq. (12). Given the high computation costs of model estimation due to the iterative algorithm with a Bayesian estimation of the parameters, the autocorrelation effect is considered only for the models with the random effects. Table 3 summarizes the model specifications for the simulation.

In terms of setting parameters for the CHAID tree induction method, alpha significance levels of the best possible split and merge are set to 0.05 , while the tree stops growing if the number of observations at the terminal node is less than $N$ / 100, where $N$ is the sample size of the training data set. For the MCMCglmm, all models were run for 11,000 draws with a burn-in period of 1000 and a thinning interval of 10 . This means the posterior mean values were calculated from the posterior distribution of every single draw from 10,001 to 50,000 , which results in a sample size of 40,000 . In order to avoid the autocorrelation issue during the MCMC sampling, the model estimates at convergence were diagnosed using the trace and autocorrelation plots.

\subsection{Simulation results}

For all models, the iterative process of the proposed algorithm was continued until $|\Delta \mathrm{DIC}|<10$. As a goodness-of-fit measure, the probabilistic theta is used which is given by (Arentze and Timmermans, 2005),

$$
e=\sum_{p} \operatorname{Pr}(t \rightarrow p) \sum_{j} \operatorname{Pr}(j \mid p) \operatorname{Pr}^{\prime}(j \mid p)=\sum_{p}\left(\frac{f_{p}}{n}\right) \sum_{j}\left(\frac{f_{j p}}{f_{p}}\right)^{2}
$$

where $e$ is the probability of correctly predicting the choice for any given observation $t$ in the same sample, $\operatorname{Pr}(t \rightarrow p)$ is the probability that $t$ belongs to terminal node $p, \operatorname{Pr}(j \mid p)$ is the probability that choice $j$ is observed in cases belonging to terminal node $p$ and $\operatorname{Pr}^{\prime}(j \mid p)$ is the probability of predicting $j$ in those cases. Given that the probabilistic action-assignment rule has been used, the predicted and observed probabilities are same (i.e., $\operatorname{Pr}(j \mid p)=\operatorname{Pr}^{\prime}(j \mid p)$ ). $n$ is the total number of cases, $f_{p}$ is the number of cases at terminal node $p$ and $f_{j p}$ is the number of cases at terminal node $p$ with observed choice 
Table 4

\begin{tabular}{lllllll}
\multicolumn{2}{l}{ Model summary. } \\
\hline Model & N. iterations at convergence & N. decision nodes & N. terminal nodes & $e_{0}$ & $e$ & $e_{\text {incr }}$ \\
\hline 1 & - & 21 & 29 & 0.453 & 0.768 & 0.577 \\
2 & 23 & 17 & 21 & 0.453 & 0.956 & 0.908 \\
3 & 26 & 11 & 16 & 0.453 & 0.975 & 0.948 \\
4 & 30 & 7 & 10 & 0.453 & 0.980 & 0.959 \\
5 & 26 & 9 & 15 & 0.453 & 0.976 & 0.956 \\
\hline
\end{tabular}

Table 5

Posterior mean estimates of random effect variances (baseline category: no charging).

\begin{tabular}{lllll}
\hline & Model 2 & Model 3 & Model 4 & Model 5 \\
\hline Random effects (at iteration 1) & & & & \\
$\hat{\sigma}_{\text {individual: private charging }}^{2}$ & 3.152 & 3.110 & 3.369 & 3.549 \\
$\hat{\sigma}_{\text {individual:public charging }}^{2}$ & $(1.55,4.87)$ & $(1.56,4.65)$ & $(1.69,4.64)$ & $(1.94,5.32)$ \\
$\hat{\sigma}_{\text {individual:semi-public charging }}^{2}$ & 1.541 & 1.509 & 1.490 & 1.174 \\
& $(0.35,2.45)$ & $(0.42,2.35)$ & $(0.36,2.90)$ & $(0.37,1.83)$ \\
$\hat{\sigma}_{\text {individual: fast charging }}^{2}$ & 0.521 & 0.500 & 0.527 & 0.744 \\
& $(0.17,0.82)$ & $(0.20,0.99)$ & $(0.15,0.97)$ & $(0.26,1.30)$ \\
Random effects (at convergence) & 2.237 & 2.274 & 2.678 & 2.609 \\
$\hat{\sigma}_{\text {individual: } \text { :rivate charging }}^{2}$ & $(0.64,3.39)$ & $(0.69,3.88)$ & $(0.66,4.99)$ & $(0.65,4.30)$ \\
$\hat{\sigma}_{\text {individual:public charging }}^{2}$ & 0.355 & 0.347 & 0.255 & 0.195 \\
$\hat{\sigma}_{\text {individual:semi-public charging }}^{2}$ & $(0.12,0.63)$ & $(0.16,0.60)$ & $(0.14,0.40)$ & $(0.11,0.29)$ \\
$\hat{\sigma}_{\text {individual: fast charging }}^{2}$ & 0.223 & 0.314 & 0.397 & 0.322 \\
& $(0.12,0.41)$ & $(0.12,0.52)$ & $(0.14,0.68)$ & $(0.17,0.49)$ \\
& 0.263 & 0.218 & 0.249 & 0.403 \\
& $(0.12,0.45)$ & $(0.11,0.33)$ & $(0.10,0.42)$ & $(0.19,0.66)$ \\
& 0.246 & 0.413 & 0.291 & 0.311 \\
& $(0.12,0.39)$ & $(0.13,0.74)$ & $(0.14,0.45)$ & $(0.17,0.47)$ \\
\hline
\end{tabular}

Note: 95\% highest posterior density (HPD) intervals are in parentheses. HPD interval is the Bayesian analogue of a confidence interval. The error variance is fixed at certain value for the non-Gaussian response (Hadfield, 2016). The baseline category is set as "no charging".

$j$. By comparing $e$ with that of a null model, $e_{0}$, which only consists of the root node, it is possible to measure the relative performance of each model by its $e_{\text {incr }}$.

$$
\begin{aligned}
& e_{0}=\sum_{j} \operatorname{Pr}(j) \operatorname{Pr}^{\prime}(j)=\sum_{j}\left(\frac{f_{j}}{n}\right)^{2} \\
& e_{\text {incr }}=\frac{e-e_{0}}{1-e_{0}}
\end{aligned}
$$

It should be noted that $e_{i n c r}$ indicates the increase in likelihood as a ratio of the maximum increase that is possible given the null model. Thus, this indicator is comparable to the (log) likelihood ratio commonly used as a measure of goodness-offit for discrete choice models.

Table 4 provides the summary of the model results based on the training dataset $(N=9873)$. All models successfully converge after some iterations. The number of decision nodes and terminal nodes in the tree are noticeably reduced when the proposed algorithm is applied. Incorporating the random effects (Model 2-Model 5) results in a marked improvement in model fit over the standard CHAID (Model 1), as well as more interpretable results with fewer predictors. In other words, a significant amount of heterogeneity among PEV users may exist in the data. The inclusion of temporal autocorrelation (Model 4, Model 5) also results in a better model fit although not significant.

Table 5 presents the estimated variance components at the first iteration and at convergence. The values reported are the elements of the estimated covariance matrix $\hat{D}$. Note that the total variance explained by the random effect drops significantly at convergence. In addition, the share of explained variance at the first iteration is similar across models (in order of private charging, fast charging, public charging and semi-public charging), but this weakens with an increasing number of iterations, and eventually the share of variance differs from the uniform distribution at convergence.

To determine whether the model successfully converged using MCMCglmm, a time series of the parameter for the MCMC iterations can be diagnosed. If the time series, a trace of the sampled posterior, does not show a trend, one can conclude that the Markov chain is well-mixed and the model reaches convergence (Hadfield, 2016). The left side of Fig. 2 present the trace plots of the random effect variance of Model 5 at convergence, while the right side shows the corresponding posterior density distributions. The trace plots show that the Markov chains appear to have reached a stationary distribution as no 

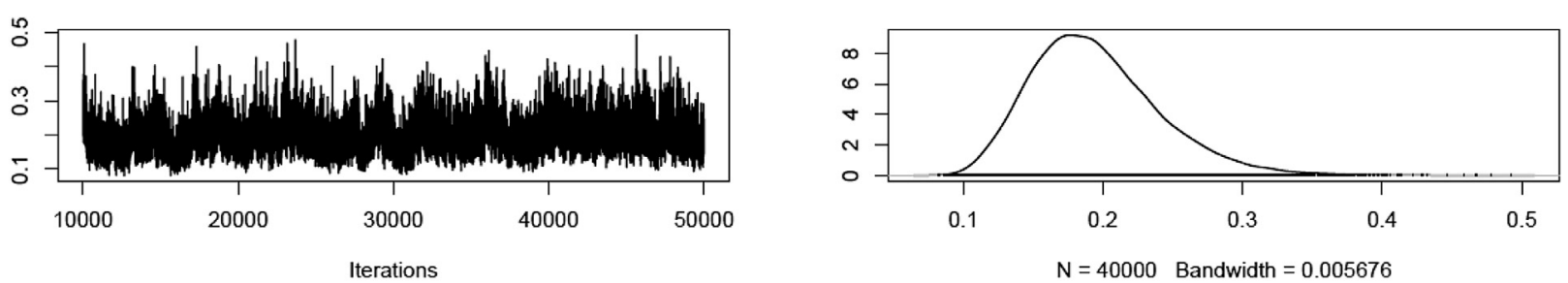

(a) Private charging
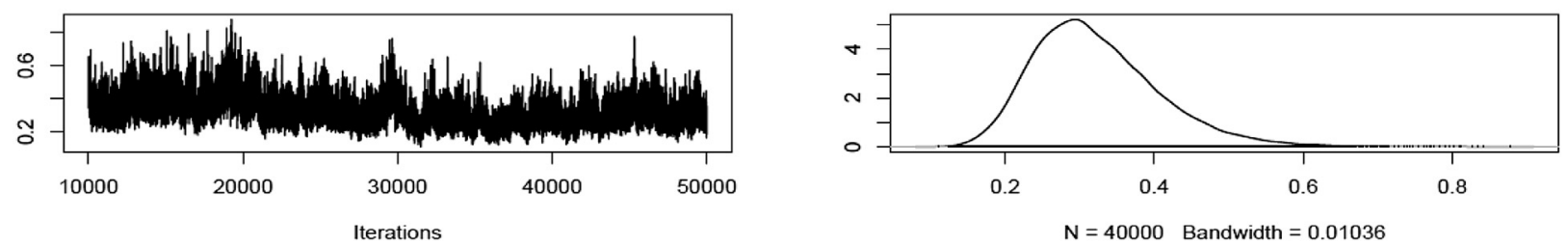

(b) Public charging
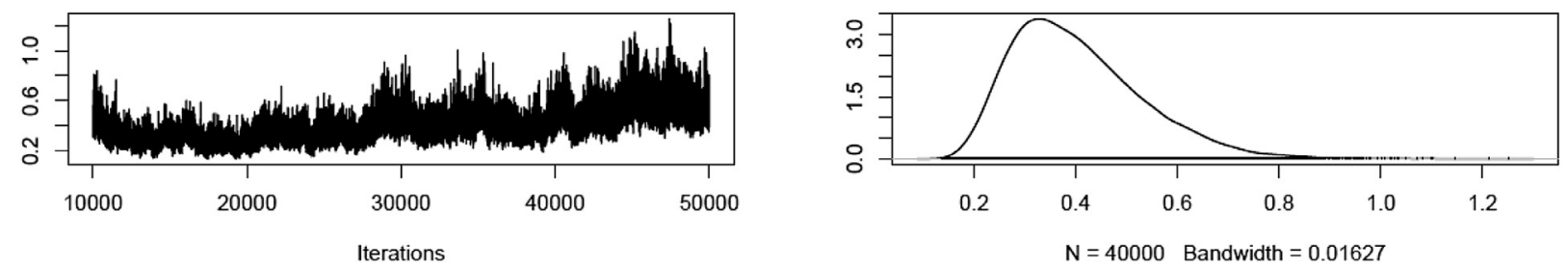

(c) Semi-public charging
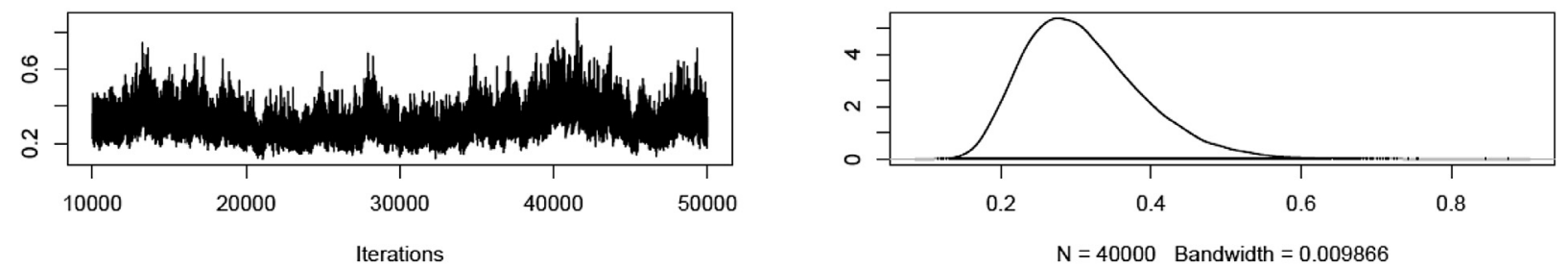

(d) Fast charging

Fig. 2. Trace plot of the random effect variance of Model 5 at convergence: (a) private charging, (b) public charging, (c) semi-public charging and (d) fast charging.

significant trends could be found. The posterior density plots show a unimodal, smooth posterior distribution, implying that the desired stabilization and convergence of the parameters are met.

\subsection{Predictive performance on out-of-sample data}

For the out-of-sample prediction, dynamic decision trees may be applied to two different cases. There can be a situation when we predict the future events for individuals observed in the sample (i.e., observation-level prediction). Alternatively, we may need to predict the future events for new individuals who are not observed in the sample (i.e., individual-level prediction). For the latter case, since the random effects covariates, $\boldsymbol{Z}_{\boldsymbol{i} \boldsymbol{j}}$, are not observable, the random effects, $\boldsymbol{b}_{\boldsymbol{i}}$, are set to zero for new individuals. Hence, the performance between the models with and without random effects will be comparable if the sample size is large enough so that the fixed effects component, $f_{j}\left(\boldsymbol{X}_{\mathbf{i}}\right)$, is well estimated. For the predictive accuracy test in this study, we considered the former case, so that the data is split into the set for training (75\%) and the test set (25\%), while the number of individuals is kept constant.

To evaluate the predictive performance of the classification tree, one can rely on measures for binary classifiers. The most commonly used are accuracy, sensitivity and specificity derived from the confusion matrix, which cross-tabulates the 


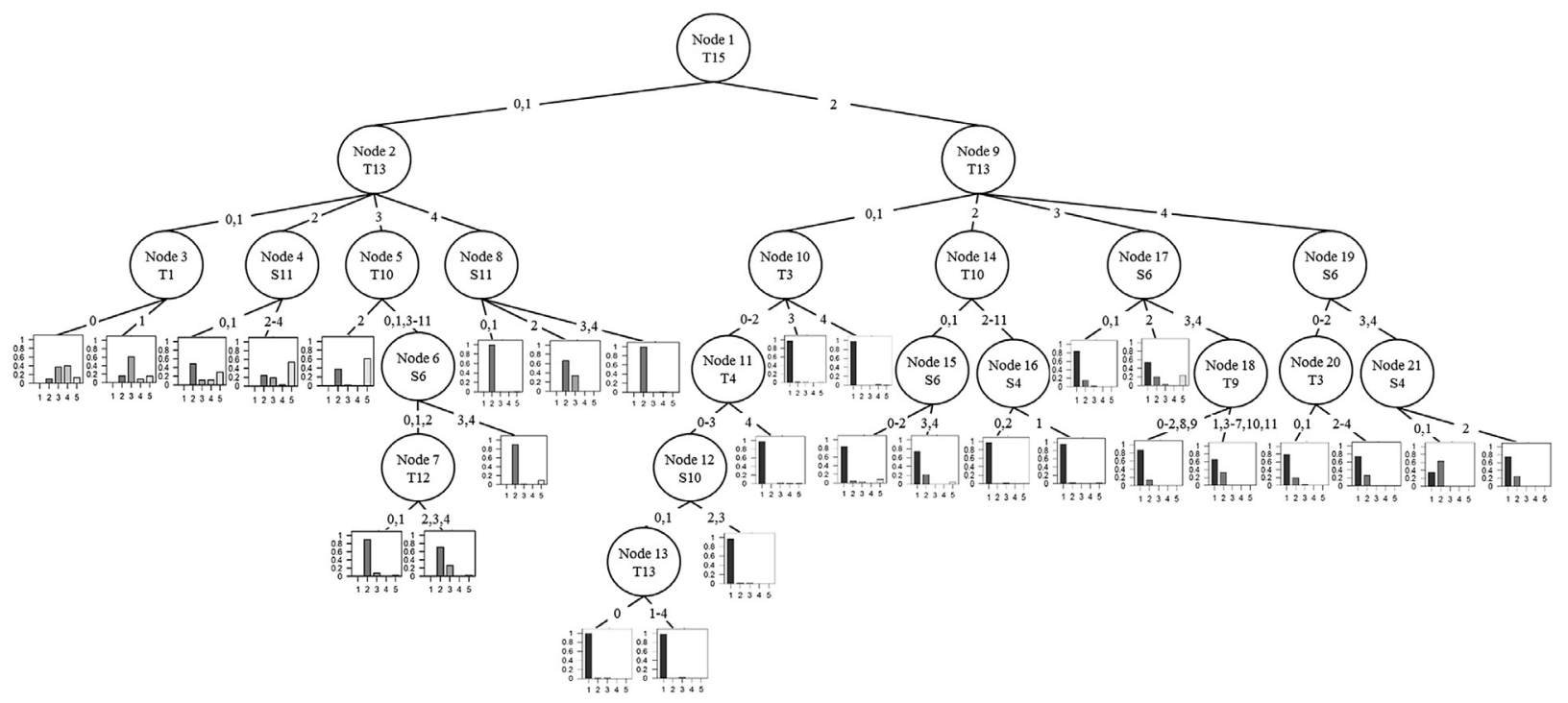

Fig. 3. Estimated CHAID tree structure (Model 1).

observed and predicted responses.

$$
\operatorname{Accuracy}(A c c)=\frac{T P+T N}{T P+T N+F P+F N}
$$

where TP, TN, FP and FN denote the number of true positives, true negatives, false positives, and false negatives, respectively.

However, this measure may yield biased results for multi-class classification problems (i.e., more than two response classes) if the data represent an imbalanced class distribution (Kautz et al., 2017). We considered several performance measures, which overcome this limitation. The balanced accuracy, F1-score and G-mean, which are, respectively, the arithmetic mean of sensitivity and specificity, the harmonic mean of sensitivity and precision, and the geometric mean of sensitivity and precision, have been proposed to that end. Cohen's Kappa measure is also a useful metric to assess the performance of the multi-class classifier, while compensating for the measured prediction accuracy merely by chance (i.e., random accuracy $\left.=\frac{(T N+F P)(T N \times F N)+(F N \times T P)(F P \times T P)}{(T P+T N+F P+F N)^{2}}\right)($ Ben-David, 2007).

$$
\begin{aligned}
& \text { Balanced accuracy }(\text { BAcc })=\frac{\text { Sensitivity } \times \text { Specificity }}{2}=\frac{1}{2}\left(\frac{T P}{T P+F N}+\frac{T N}{T N+F P}\right) \\
& F 1-\text { score }=\frac{2 \times \text { Sensitivity } \times \text { Precision }}{\text { Sensitivity }+ \text { Precision }}=\frac{2 \times \frac{T P}{T P+F N} \times \frac{T P}{T P+F P}}{\frac{T P}{T P+F N}+\frac{T P}{T P+F P}} \\
& G-\text { mean }=\sqrt{\text { Sensitivity } \times \text { Precision }}=\sqrt{\frac{T P}{T P+F N} \times \frac{T P}{T P+F P}}
\end{aligned}
$$

$$
\text { Cohen's Kappa }(\kappa)=\frac{\text { Accuracy }- \text { Random accuracy }}{1-\text { Random accuracy }}
$$

The predictions were obtained from a total of 100 different draws based on the predicted response distributions from the fitted trees. Table 6 provides the results of the performance comparison between the models. The overall performance measure is calculated as the average of the alternative-wise measures. When comparing the accuracy (Acc) with other performance measures tuned for the imbalanced data problem, significant adjustments have been made for the response alternatives with few observations (e.g., alternative 3 and 4). In addition, it seems no overfitting occurs since no significant drops are seen in most of the measures between the training and test sets.

Compared to the standard CHAID tree (Model 1), the trees with the random effects (Model 2 - Model 5) show better performance for out-of-sample prediction, even for smaller tree sizes. The results show that the proposed algorithm improved model parsimony and its interpretability by taking unobserved heterogeneity and autocorrelation within individuals into account. Overall, Model 5 shows the best predictive performance for both training and test data. 


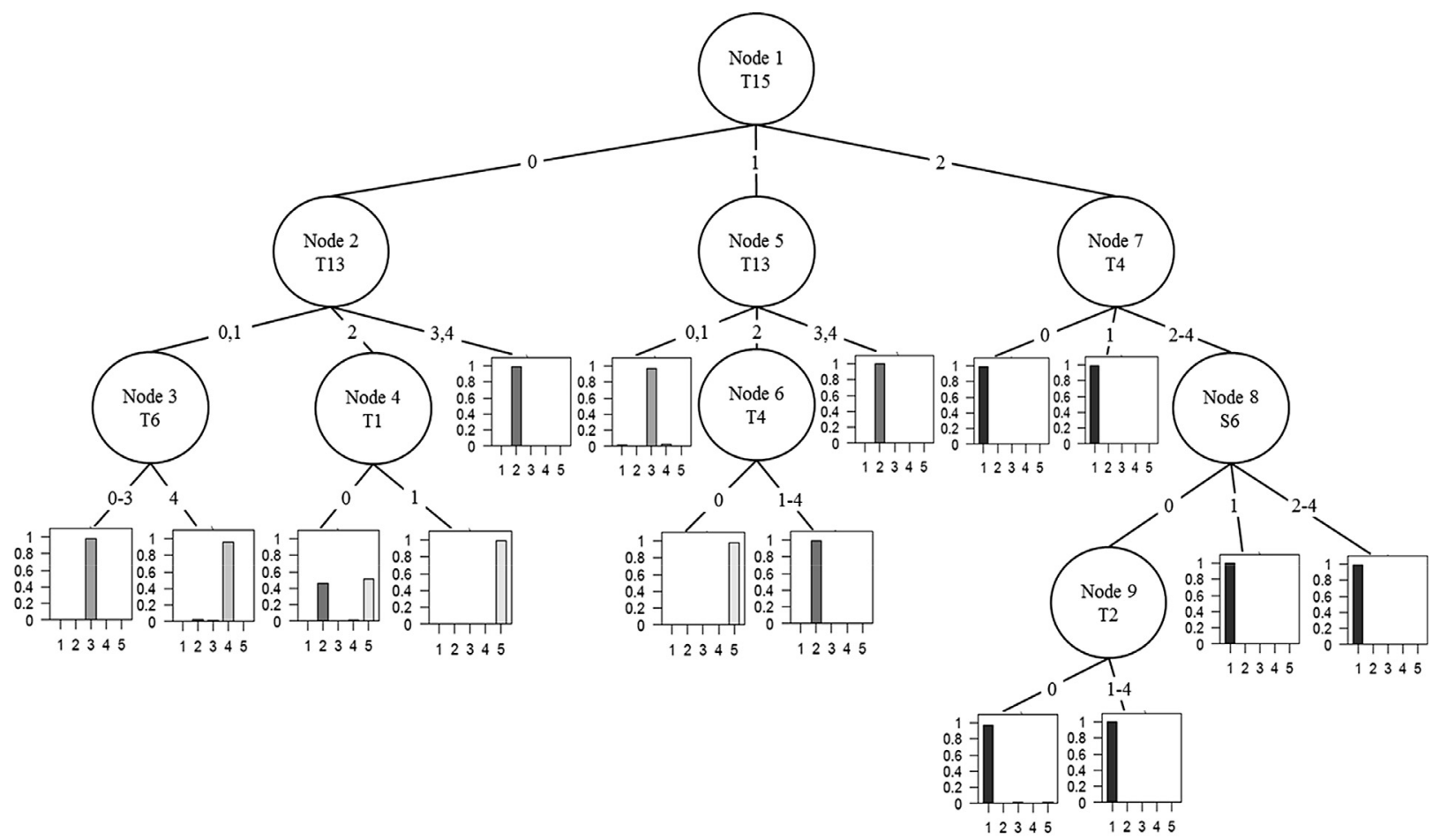

Fig. 4. Estimated CHAID tree structure (Model 5).

Table 6

Predictive accuracy of the models.

\begin{tabular}{|c|c|c|c|c|c|c|c|c|c|c|c|}
\hline \multirow[t]{2}{*}{ Model } & \multirow[t]{2}{*}{ Alt } & \multicolumn{5}{|c|}{ Training set $(N=9873, I=73)$} & \multicolumn{5}{|c|}{ Test set $(N=3290, I=73)$} \\
\hline & & Acc & BAcc & F1-score & G-mean & $\kappa$ & $\overline{A c c}$ & BAcc & F1-score & G-mean & $\kappa$ \\
\hline \multirow[t]{5}{*}{1} & 1 & 0.884 & 0.876 & 0.907 & 0.907 & 0.753 & 0.886 & 0.879 & 0.907 & 0.907 & 0.759 \\
\hline & 2 & 0.827 & 0.764 & 0.638 & 0.638 & 0.525 & 0.822 & 0.756 & 0.635 & 0.635 & 0.518 \\
\hline & 3 & 0.921 & 0.635 & 0.307 & 0.307 & 0.265 & 0.923 & 0.629 & 0.269 & 0.271 & 0.229 \\
\hline & 4 & 0.970 & 0.567 & 0.146 & 0.146 & 0.130 & 0.972 & 0.558 & 0.143 & 0.145 & 0.129 \\
\hline & 5 & 0.910 & 0.603 & 0.270 & 0.271 & 0.223 & 0.913 & 0.674 & 0.402 & 0.402 & 0.356 \\
\hline \multicolumn{2}{|l|}{ Overall } & 0.903 & 0.689 & 0.454 & 0.454 & 0.379 & 0.903 & 0.699 & 0.472 & 0.472 & 0.398 \\
\hline \multirow[t]{5}{*}{2} & 1 & 0.908 & 0.886 & 0.930 & 0.931 & 0.798 & 0.910 & 0.889 & 0.931 & 0.932 & 0.804 \\
\hline & 2 & 0.860 & 0.796 & 0.696 & 0.696 & 0.606 & 0.855 & 0.787 & 0.690 & 0.691 & 0.595 \\
\hline & 3 & 0.939 & 0.671 & 0.401 & 0.403 & 0.369 & 0.941 & 0.669 & 0.368 & 0.368 & 0.337 \\
\hline & 4 & 0.978 & 0.511 & 0.042 & 0.048 & 0.034 & 0.977 & 0.535 & 0.109 & 0.121 & 0.099 \\
\hline & 5 & 0.935 & 0.646 & 0.389 & 0.402 & 0.357 & 0.929 & 0.648 & 0.400 & 0.413 & 0.365 \\
\hline \multicolumn{2}{|l|}{ Overall } & 0.924 & 0.702 & 0.492 & 0.496 & 0.433 & 0.922 & 0.706 & 0.499 & 0.505 & 0.440 \\
\hline \multirow[t]{5}{*}{3} & 1 & 0.912 & 0.887 & 0.933 & 0.935 & 0.805 & 0.910 & 0.887 & 0.931 & 0.933 & 0.804 \\
\hline & 2 & 0.869 & 0.784 & 0.692 & 0.696 & 0.609 & 0.858 & 0.770 & 0.675 & 0.681 & 0.586 \\
\hline & 3 & 0.942 & 0.679 & 0.423 & 0.425 & 0.392 & 0.944 & 0.679 & 0.392 & 0.392 & 0.362 \\
\hline & 4 & 0.978 & 0.531 & 0.096 & 0.107 & 0.088 & 0.978 & 0.561 & 0.177 & 0.192 & 0.168 \\
\hline & 5 & 0.925 & 0.676 & 0.407 & 0.408 & 0.367 & 0.920 & 0.681 & 0.425 & 0.426 & 0.382 \\
\hline \multirow{6}{*}{$\begin{array}{l}\text { Overall } \\
4\end{array}$} & & 0.925 & 0.711 & 0.510 & 0.514 & 0.452 & 0.922 & 0.715 & 0.520 & 0.525 & 0.460 \\
\hline & 1 & 0.909 & 0.890 & 0.930 & 0.931 & 0.801 & 0.917 & 0.900 & 0.935 & 0.936 & 0.820 \\
\hline & 2 & 0.856 & 0.803 & 0.698 & 0.698 & 0.603 & 0.859 & 0.808 & 0.712 & 0.712 & 0.618 \\
\hline & 3 & 0.942 & 0.683 & 0.428 & 0.430 & 0.398 & 0.943 & 0.681 & 0.391 & 0.391 & 0.361 \\
\hline & 4 & 0.978 & 0.528 & 0.090 & 0.101 & 0.081 & 0.977 & 0.524 & 0.080 & 0.091 & 0.071 \\
\hline & 5 & 0.933 & 0.617 & 0.334 & 0.353 & 0.302 & 0.930 & 0.627 & 0.364 & 0.387 & 0.331 \\
\hline \multirow{6}{*}{$\begin{array}{l}\text { Overall } \\
5\end{array}$} & & 0.924 & 0.704 & 0.496 & 0.502 & 0.437 & 0.925 & 0.708 & 0.496 & 0.503 & 0.440 \\
\hline & 1 & 0.913 & 0.887 & 0.934 & 0.936 & 0.806 & 0.911 & 0.887 & 0.932 & 0.933 & 0.805 \\
\hline & 2 & 0.862 & 0.786 & 0.688 & 0.689 & 0.600 & 0.851 & 0.773 & 0.672 & 0.675 & 0.577 \\
\hline & 3 & 0.944 & 0.647 & 0.382 & 0.392 & 0.354 & 0.946 & 0.645 & 0.353 & 0.356 & 0.325 \\
\hline & 4 & 0.978 & 0.659 & 0.342 & 0.342 & 0.331 & 0.976 & 0.642 & 0.311 & 0.311 & 0.299 \\
\hline & 5 & 0.931 & 0.640 & 0.371 & 0.380 & 0.336 & 0.925 & 0.643 & 0.381 & 0.391 & 0.344 \\
\hline \multicolumn{2}{|l|}{ Overall } & 0.926 & 0.724 & 0.543 & 0.548 & 0.485 & 0.922 & 0.718 & 0.530 & 0.533 & 0.470 \\
\hline
\end{tabular}

Note: The figures in the table indicate the mean value of the metrics over 100 draws. 
Table 7

Impact table: Model 1 and Model 5.

\begin{tabular}{|c|c|c|c|c|c|c|c|c|c|c|c|}
\hline \multicolumn{12}{|l|}{ Model 1} \\
\hline Variable & IS & $I S_{\text {no }}$ & $I S_{\text {private }}$ & $I S_{\text {public }}$ & $I S_{\text {semi-public }}$ & $I S_{\text {fast }}$ & $M S_{n o}$ & $M S_{\text {private }}$ & $M S_{\text {public }}$ & $M S_{\text {semi-public }}$ & $M S_{\text {fast }}$ \\
\hline $\mathrm{T} 15$ & 9336.14 & 2848.86 & 3318.87 & 1496.92 & 450.33 & 1221.17 & 0.89 & -0.79 & -0.72 & -0.62 & -0.67 \\
\hline $\mathrm{T} 10$ & 5374.50 & 484.22 & 1821.12 & 153.43 & 562.16 & 2353.57 & 0.52 & 0.06 & 0.07 & 0.03 & -0.02 \\
\hline T13 & 3662.92 & 446.61 & 2000.87 & 6.36 & 285.99 & 923.09 & 0.59 & -0.46 & 0.11 & 0.17 & 0.04 \\
\hline T3 & 982.39 & 226.38 & 121.70 & 104.58 & 170.76 & 358.98 & -0.14 & -0.47 & -0.38 & -0.36 & -0.38 \\
\hline $\mathrm{T} 4$ & 919.14 & 51.46 & 257.41 & 40.98 & 27.88 & 541.41 & -0.15 & -0.72 & -0.36 & -0.46 & 0.07 \\
\hline T12 & 878.81 & 88.08 & 522.73 & 26.36 & 29.95 & 211.68 & 0.31 & 0.63 & 0.33 & 0.28 & 0.13 \\
\hline T9 & 789.99 & 39.59 & 440.14 & 49.44 & 17.54 & 243.29 & 0.51 & 0.33 & 0.07 & 0.04 & 0.05 \\
\hline S4 & 389.76 & 28.39 & 25.47 & 32.71 & 10.49 & 292.69 & -0.71 & -0.33 & 0.36 & 0.80 & 0.00 \\
\hline S6 & 224.99 & 25.98 & 80.22 & 41.24 & 21.44 & 56.11 & -0.10 & -0.53 & -0.16 & -0.27 & -0.03 \\
\hline $\mathrm{T} 1$ & 222.30 & 36.00 & 118.04 & 4.55 & 17.38 & 46.33 & -0.55 & 0.35 & -0.34 & -0.36 & 0.02 \\
\hline S10 & 93.03 & 9.99 & 33.12 & 34.81 & 3.80 & 11.30 & 0.71 & 0.52 & 0.22 & 0.16 & 0.26 \\
\hline S11 & 74.52 & 10.05 & 1.73 & 54.06 & 6.14 & 2.53 & 0.45 & -0.15 & -0.56 & -0.60 & -0.44 \\
\hline \multicolumn{12}{|l|}{ Model 5} \\
\hline Variable & IS & $I S_{n o}$ & $I S_{\text {private }}$ & $I S_{\text {public }}$ & $I S_{\text {semi-public }}$ & $I S_{\text {fast }}$ & $M S_{n o}$ & $M S_{\text {private }}$ & $M S_{\text {public }}$ & $M S_{\text {semi-public }}$ & $M S_{\text {fast }}$ \\
\hline $\mathrm{T} 15$ & 10432.28 & 2906.00 & 4797.40 & 875.55 & 557.32 & 1296.00 & 0.88 & -0.81 & -0.65 & -0.55 & -0.61 \\
\hline T13 & 5531.33 & 388.67 & 2502.38 & 494.28 & 193.23 & 1952.78 & 0.50 & -0.37 & 0.21 & 0.12 & 0.05 \\
\hline T6 & 1908.62 & 176.34 & 888.39 & 47.93 & 495.00 & 300.96 & -0.67 & 0.30 & -0.49 & -0.46 & -0.52 \\
\hline $\mathrm{T} 4$ & 888.92 & 51.99 & 233.10 & 25.05 & 33.03 & 545.75 & -0.46 & -0.93 & -0.71 & -0.81 & -0.12 \\
\hline $\mathrm{T} 2$ & 810.44 & 189.26 & 120.21 & 146.81 & 98.32 & 255.83 & -0.47 & -0.64 & -0.70 & -0.68 & -0.71 \\
\hline $\mathrm{T} 1$ & 255.91 & 54.31 & 153.42 & 6.43 & 4.22 & 37.53 & -0.73 & 0.27 & -0.57 & -0.56 & -0.22 \\
\hline S6 & 114.29 & 9.84 & 37.35 & 15.71 & 13.19 & 38.20 & -0.04 & 0.16 & -0.96 & -0.55 & -0.55 \\
\hline
\end{tabular}

\section{Discussion}

This section discusses behavioral implications of the proposed method through the comparison of impact of condition variables and dendrogram results with the standard CHAID. For the comparison, we consider Model 1 and Model 5, whereby the training set $(N=9873)$ is used for training, as examples.

\subsection{Impact of condition variables}

It is of interest to evaluate the quantitative effects of each condition variable on choice behavior, and thus to compare the behavioral differences between the two models. However, one drawback of using rule-based systems for modeling choice behavior, which are non-parametric, is that the complexity of the structures that are generated by a large set of predictors often hinders their interpretation. To overcome this problem, we used the measures developed by Arentze and Timmermans (2003) that quantify the magnitude and direction of the impact of condition variables on predicted choices. The contingency tables derived from both Model 1 and Model 5 have full information on the impact of condition variable $s$ on choice outcomes. First, the measure used for the magnitude of the impact can be written as follows.

$$
\begin{aligned}
& I S_{s}=D\left(\boldsymbol{F}_{s}, \overline{\boldsymbol{F}_{s}}\right) \\
& I S_{s i}=D\left(\boldsymbol{F}_{s i}, \overline{\boldsymbol{F}_{s i}}\right)
\end{aligned}
$$

where $D(\cdot, \cdot)$ is some measure of difference (e.g., Chi-square, the sum of absolute differences, likelihood, etc.) between contingency tables. In this study, the Chi-square statistic is used for $D$. $\boldsymbol{F}_{\boldsymbol{S}}$ is the frequency table predicted by the model for condition variable $s, \overline{\boldsymbol{F}}_{s}$ is the expected frequency table under the assumption that there is no impact of condition variable $s, \boldsymbol{F}_{s i}$ is the frequency table predicted by the model for condition variable $s$ on choice $i$, and $\overline{\boldsymbol{F}_{s i}}$ is the expected counterpart. As the equations imply, the first measure provides an indication of the overall impact of condition variable $s$ on the choice variable, while the second measure gives the impact on each choice alternative $i$. Note that the sum of the impact of $s$ across choice alternatives equals the overall impact (i.e., $I S_{s}=\sum_{i} I S_{s i}$ ).

Apart from the magnitude of the impact of condition variables, the direction of the impact is also of interest to researchers. The measure for the direction of the impact can be described as,

$$
M S_{s i}=\frac{\sum_{j=2}^{J}\left(f_{i, j}-f_{i, j-1}\right)}{\sum_{j=2}^{J}\left|f_{i, j}-f_{i, j-1}\right|}
$$

where $f_{i, j}$ is the predicted frequency of choice alternative $i$ under the $j$-th level of condition variable $s$, and $J$ is the number of levels of $s$. If the predictor has a monotonically increasing impact on choice alternative $i, M S_{s i}$ equals 1 and if it has a monotonically decreasing impact it equals -1 . In all other cases (i.e., $-1<M S_{s i}<1$ ), the impact of condition variable 
Table 8

Result of Model 5.

\begin{tabular}{|c|c|c|c|c|c|c|}
\hline \multirow[t]{2}{*}{ Terminal node $p$} & \multirow[t]{2}{*}{ Terminal node information } & \multicolumn{5}{|c|}{ Choice alternative $j$} \\
\hline & & $\begin{array}{l}\text { No } \\
\text { charging } \\
j=0\end{array}$ & $\begin{array}{l}\text { Private } \\
\text { charging } \\
j=1\end{array}$ & $\begin{array}{l}\text { Public } \\
\text { charging } \\
j=2\end{array}$ & $\begin{array}{l}\text { Semi-public } \\
\text { charging } \\
j=3\end{array}$ & $\begin{array}{l}\text { Fast } \\
\text { charging } \\
j=4\end{array}$ \\
\hline 1 & $\hat{f}_{j}\left(\boldsymbol{X}_{\boldsymbol{i}}\right)$ & 0 & -1.181 & 5.189 & -0.544 & -0.597 \\
\hline \multirow{2}{*}{$n_{p}=161$} & $n_{j p}$ & 1 & 1 & 158 & 0 & 1 \\
\hline & $\hat{\pi}_{i j t}^{C H A I D}$ & 0.006 & 0.006 & 0.981 & 0 & 0.006 \\
\hline 2 & $\hat{f}_{j}\left(\boldsymbol{X}_{\boldsymbol{i}}\right)$ & 0 & 1.622 & 1.01 & 5.489 & -0.673 \\
\hline \multirow{2}{*}{$n_{p}=123$} & $n_{j p}$ & 0 & 3 & 2 & 118 & 0 \\
\hline & $\hat{\pi}_{i j t}^{C H A I D}$ & 0 & 0.024 & 0.016 & 0.959 & 0 \\
\hline 3 & $\hat{f}_{j}\left(\boldsymbol{X}_{\boldsymbol{i}}\right)$ & 0 & 6.796 & 1.002 & 2.638 & 6.712 \\
\hline \multirow{2}{*}{$n_{p}=118$} & $n_{j p}$ & 0 & 54 & 1 & 2 & 61 \\
\hline & $\hat{\pi}_{i j t}^{C H A I D}$ & 0 & 0.458 & 0.008 & 0.017 & 0.517 \\
\hline 4 & $\hat{f}_{j}\left(\boldsymbol{X}_{\boldsymbol{i}}\right)$ & 0 & 1.115 & 1.646 & 1.286 & 6.898 \\
\hline \multirow{2}{*}{$n_{p}=245$} & $n_{j p}$ & 0 & 0 & 2 & 1 & 242 \\
\hline & $\hat{\pi}_{i j t}^{C H A I D}$ & 0 & 0 & 0.008 & 0.004 & 0.988 \\
\hline 5 & $\hat{f}_{j}\left(\boldsymbol{X}_{\boldsymbol{i}}\right)$ & 0 & 7.235 & 0.112 & 0.674 & 0.674 \\
\hline \multirow{2}{*}{$n_{p}=1138$} & $n_{j p}$ & 0 & 1130 & 2 & 3 & 3 \\
\hline & $\hat{\pi}_{i j t}^{C H A I D}$ & 0 & 0.993 & 0.002 & 0.003 & 0.003 \\
\hline 6 & $\hat{f}_{j}\left(\boldsymbol{X}_{\boldsymbol{i}}\right)$ & 0 & -1.407 & 5.642 & 1.16 & 0.924 \\
\hline \multirow[t]{2}{*}{$n_{p}=171$} & $n_{j p}$ & 2 & 0 & 165 & 4 & 0 \\
\hline & $\hat{\pi}_{i j t}^{C H A I D}$ & 0.012 & 0 & 0.965 & 0.023 & 0 \\
\hline 7 & $\hat{f}_{j}\left(\boldsymbol{X}_{\boldsymbol{i}}\right)$ & 0 & 0.822 & 0.349 & 1.088 & 6.74 \\
\hline \multirow[t]{2}{*}{$n_{p}=106$} & $n_{j p}$ & 0 & 1 & 0 & 1 & 104 \\
\hline & $\hat{\pi}_{i j t}^{C H A I D}$ & 0 & 0.009 & 0 & 0.009 & 0.981 \\
\hline 8 & $\hat{f}_{j}\left(\boldsymbol{X}_{\boldsymbol{i}}\right)$ & 0 & 4.994 & 0.31 & -0.617 & -1.559 \\
\hline \multirow{2}{*}{$n_{p}=126$} & $n_{j p}$ & 1 & 124 & 0 & 1 & 0 \\
\hline & $\hat{\pi}_{i j t}^{C H A I D}$ & 0.008 & 0.984 & 0 & 0.008 & 0 \\
\hline 9 & $\hat{f}_{j}\left(\boldsymbol{X}_{\boldsymbol{i}}\right)$ & 0 & 9.725 & 2.649 & 2.87 & 2.224 \\
\hline \multirow[t]{2}{*}{$n_{p}=718$} & $n_{j p}$ & 0 & 718 & 0 & 0 & 0 \\
\hline & $\hat{\pi}_{i j t}^{C H A I D}$ & 0 & 1 & 0 & 0 & 0 \\
\hline 10 & $\hat{f}_{j}\left(\boldsymbol{X}_{\boldsymbol{i}}\right)$ & 0 & -8.022 & -6.189 & -5.888 & -6.178 \\
\hline \multirow[t]{2}{*}{$n_{p}=1565$} & $n_{j p}$ & 1549 & 0 & 3 & 11 & 2 \\
\hline & $\hat{\pi}_{i j t}^{C H A I D}$ & 0.99 & 0 & 0.002 & 0.007 & 0.001 \\
\hline 11 & $\hat{f}_{j}\left(\boldsymbol{X}_{\boldsymbol{i}}\right)$ & 0 & -7.89 & -6.196 & -5.966 & -6.038 \\
\hline \multirow[t]{2}{*}{$n_{p}=1258$} & $n_{j p}$ & 1240 & 2 & 5 & 4 & 7 \\
\hline & $\hat{\pi}_{i j t}^{C H A I D}$ & 0.986 & 0.002 & 0.004 & 0.003 & 0.006 \\
\hline 12 & $\hat{f}_{j}\left(\boldsymbol{X}_{\boldsymbol{i}}\right)$ & 0 & -7.771 & -6.242 & -5.703 & -6.702 \\
\hline \multirow[t]{2}{*}{$n_{p}=177$} & $n_{j p}$ & 171 & 0 & 2 & 1 & 3 \\
\hline & $\hat{\pi}_{i j t}^{C H A I D}$ & 0.966 & 0 & 0.011 & 0.006 & 0.017 \\
\hline 13 & $\hat{f}_{j}\left(\boldsymbol{X}_{\boldsymbol{i}}\right)$ & 0 & -7.673 & -6.203 & -5.744 & -6.727 \\
\hline \multirow[t]{2}{*}{$n_{p}=655$} & $n_{j p}$ & 654 & 0 & 0 & 1 & 0 \\
\hline & $\hat{\pi}_{i j t}^{C H A I D}$ & 0.998 & 0 & 0 & 0.002 & 0 \\
\hline 14 & $\hat{f}_{j}\left(\boldsymbol{X}_{\boldsymbol{i}}\right)$ & 0 & -7.805 & -6.231 & -5.811 & -6.822 \\
\hline \multirow[t]{2}{*}{$n_{p}=1189$} & $n_{j p}$ & 1189 & 0 & 0 & 0 & 0 \\
\hline & $\hat{\pi}_{i j t}^{C H A I D}$ & 1 & 0 & 0 & 0 & 0 \\
\hline 15 & $\hat{f}_{j}\left(\boldsymbol{X}_{\boldsymbol{i}}\right)$ & 0 & -7.931 & -6.272 & -5.801 & -6.745 \\
\hline \multirow[t]{2}{*}{$n_{p}=2123$} & $n_{j p}$ & 2103 & 1 & 8 & 11 & 0 \\
\hline & $\hat{\pi}_{i j t}^{C H A I D}$ & 0.991 & 0 & 0.004 & 0.005 & 0 \\
\hline
\end{tabular}

Note: The predicted fixed effects on link scale for the baseline-category, $\hat{f}_{0}\left(\boldsymbol{X}_{\boldsymbol{i}}\right)$, is equal to 0 .

$s$ on choice alternative $i$ is non-monotonous represented by the sign across the range of predictors. Note that $M S_{s i}$ is only informative for ordinal or binary condition variables, as it represents a coefficient of monotonicity of impacts across adjacent categories; it is not meaningful for condition variables that are unordered polytomous.

Table 7 provides the impact table for Model 1 and Model 5. The condition variables chosen by the models are listed in order of decreasing impact on the choice variable (the first column). For both models, socio-demographic variables (S1S11) have a limited impact on charging station choice, while time-varying travel related variables (T1-T15) have significant impact. This result indicates that the principles and heuristics underlying day-to-day charging station choice can largely be understood in terms of the time-varying situational context rather than socio-demographic profiles of users. Especially, State-of-battery (T15) is by far the most influential predictor for both models, and its impact varies across choice alternatives. With regard to the direction of impact, the sign of $M S_{s i}$ suggests a positive impact of State-of-battery (T15) on no charging occasion $\left(M S_{n o}\right)$, while the impact is negative on charging occasions $\left(M S_{\text {private }}, M S_{\text {public }}, M S_{\text {semi-public }}, M S_{\text {fast }}\right)$. The signs are in line with our expectation that high state-of-battery leads to a decrease in charging rate. Main purpose of a trip to charging 
occasion (T10) is the second most important variable for Model 1 with the highest impact on fast charging station choice. The measure for the direction of this impact, $M S_{T 10, i}$, has no meaning since main purpose of a trip is a purely nominal variable. Interestingly, however, this variable no longer exists in Model 5. Moreover, six more condition variables included in Model 1 were not chosen for Model 5. In descending order of impact, these are Main purpose of a trip to charging occasion (T10), Average travel speed of a trip to charging occasion (T3), Total stay percentage at previous location (T12), Main purpose of a previous trip to charging occasion (T9), Pay for charging at workplace (S4), Number of vehicles in the household (S10), Number of household members (S11). Instead, Travel distance of a next trip to charging occasion (T6) and Travel time of a trip to the location of charging occasion (T2) newly appeared with modest impacts in Model 5.

\subsection{Estimated tree structure}

Fig. 3 provides the standard CHAID tree (Model 1) fitted to the training data. The tree consists of 4 individual-level sociodemographic variables (S4, S6, S10 and S11) and 8 observation-level time-varying travel-related variables (T1, T3, T4, T9, T10, T12, T13 and T15). Each decision node in the decision tree, which consists of a set of decision rules, provides valuable information describing charging station choice behavior of PEV users. Not surprisingly, the first split of the tree (root node) is represented by State-of-battery (T15). More precisely, this variable acts as a proxy for charging or not charging. The high State-of-battery (T15) (category 2: 66-100\%) tends to delay PEV users' charging activity. The second split of the tree is Total stay percentage at current location for charging occasion (T13). The higher the value of this variable, the more likely a PEV user is to charge at home. Understandably, charging station choice is also attributed to socio-demographic variables (e.g., presence of private charging station, presence of charging station at workplace), which define the characteristics of the PEV user.

Compared to the standard CHAID tree, the fitted tree of Model 5 as shown in Fig. 4 is reduced in size, and consists of only 1 socio-demographic variable (S6) and 6 time-varying variables (T1, T2, T4, T6, T13 and T15). The reduced number of socio-demographic attributes can be explained, as in the previous impact table, by arguing that a certain portion of the between-individual variance is explained by the random effect. This is particularly evident for no charging dominant terminal nodes in that 18 terminal nodes that split on category 2 of State-of-battery (T15) are reduced to 6 terminal nodes. The trimmed tree structure is consistent with the results obtained for CART regression trees (Hajjem et al., 2011; Sela and Simonoff, 2012).

Table 8 provides more detailed information about the terminal nodes of the tree of Model 5. Another important implication can be derived by comparing the degree of dispersion of the distribution at the terminal nodes of each tree. The probabilistic action states of the standard CHAID tree are going to be deterministic when the proposed method is applied. That is to say, the method significantly reduces the impurity of the terminal nodes. It gives more robust results in terms of model uncertainty. An exception is terminal node 3 of Model 5 because the number of observations at the node reaches its minimum value for further splitting (remember the minimum number of observations to split the node is set to $N / 100$, which equals 99 for the training set).

\section{Conclusions and future research}

One of the problems in the transformation of static computational process models of activity-travel behavior to dynamic models is that the decision rules, captured in the probabilistic decision trees, have not considered the issue of repeated measurement. In this paper, therefore, we suggested an approach addressing this problem, elaborating earlier work on regression trees, and illustrated its application in the context of longitudinal data on charging station choice behavior of PEV users., The predictive accuracy of the proposed approach suggests improved model parsimony and interpretability even for small tree sizes. More importantly, the panel effects could be estimated.

The paper is not without its limitations. Because the suggested approach is based on Monte Carlo processes, different runs of the probabilistic decision rules will result in different outcomes. Hence, to assess the degree of uncertainty involved, it is relevant to conduct an uncertainty analysis of the model. Also, for the present small-scale model, the use of Monte Carlo simulation seems appropriate and feasible. Larger scale computational process models may, however, require faster solutions. Applying scrambled Halton draws or Latin hypercubes as has been found beneficial for the Albatross model system (Rasouli, 2016) may be further investigated. Moreover, the test of the proposed algorithm to the other nonparametric treebased classifiers with different sample sizes is recommended.

\section{Acknowledgments}

The authors would like to thank the anonymous reviewers for their valuable comments and suggestions.

\section{References}

Agresti, A., 2013. Categorical Data Analysis. John Wiley \& Sons, Hoboken, NJ, pp. 267-313.

Anastasopoulos, P.C., Fountas, G., Sarwar, M.T., Karlaftis, M.G., Sadek, A.W., 2017. Transport habits of travelers using new energy type modes: a random parameters hazard-based approach of travel distance. Transp. Res. Part C 77, 516-528. 
Arentze, T.A., Hofman, F., Mourik, H.V., Timmermans, H.J.P., Wets, G., 2000. Using decision tree induction systems for modeling space-time behavior. Geog. Anal. 32 (4), 330-350.

Arentze, T.A., Timmermans, H.J.P., 2003. Measuring impacts of condition variables in rule-based models of space-time choice behavior: method and empirical illustration. Geog. Anal. 35 (1), 24-45.

Arentze, T.A., Timmermans, H.J.P., 2004. A learning-based transportation oriented simulation system. Transp. Res. Part B 38 (7), 613-633.

Arentze, T.A., Timmermans, H.J.P., 2005. ALBATROSS Version 2.0. A Learning Based Transportation Oriented Simulation System. EIRASS, Eindhoven.

Arentze, T.A., Timmermans, H.J.P., 2009. A need-based model of multi-day, multi-person activity generation. Transp. Res. Part B 43 (2), $251-265$.

Arentze, T.A., Timmermans, H.J.P., 2012. Travel demand modeling: conceptual developments and perspectives. Transp. Lett. 4 (2), $79-92$.

Auld, J., Rashidi, T.H., Javanmardi, M., Mohammadian, A., 2011. Dynamic activity generation model using competing hazard formulation. Transp. Res. Rec. (2254) 28-35.

Ben-David, A, 2007. A lot of randomness is hiding in accuracy. Eng. Appl. Artif. Intell. 20 (7), 875-885.

Breiman, L., Friedman, J., Stone, C.J., Olshen, R.A., 1984. Classification and Regression Trees. Wadsworth International Group, Belmont.

Charoniti, E., Rasouli, S., Timmermans, H.J.P., 2017. Context-dependent latent class behavioral mixture model of utility maximization and regret minimization decision-making under uncertainty. Presented at 96th Annual Meeting of the Transportation Research Board, Washington, D.C.

Chatterjee, K, 2011. Modelling the dynamics of bus use in a changing travel environment using panel data. Transportation 38 (3), $487-509$.

Cherchi, E., Cirillo, C., de Dios Ortúzar, J., 2017. Modelling correlation patterns in mode choice models estimated on multiday travel data. Transp. Res. Part A $96,146-153$.

Chib, S., 2008. Panel data modeling and inference: A Bayesian primer. In: Matyas, L., Sevestre, P. (Eds.), The Econometrics of Panel Data, 3rd ed.. Springer-Verlag, Berlin, Heidelberg, pp. 479-515.

Cirillo, C., Axhausen, K.W., 2010. Dynamic model of activity-type choice and scheduling. Transportation 37 (1), $15-38$.

Daina, N., Sivakumar, A., Polak, J.W., 2017. Electric vehicle charging choices: Modelling and implications for smart charging services. Transp. Res. Part C 81, 36-56.

Feng, T., Timmermans, H.J.P., 2013. Transportation mode recognition using GPS and accelerometer data. Transp. Res. Part C 37, 118-130.

Feng, T., Timmermans, H.J.P., 2015. Detecting activity type from GPS traces using spatial and temporal information. Eur. J. Transp. Infrastruct. Res. 15 (4), $662-674$.

Fu, W., Simonoff, J.S., 2015. Unbiased regression trees for longitudinal and clustered data. Comput. Stat. Data Anal. 88, 53-74.

Geurs, K.T., Thomas, T., Bijlsma, M., Douhou, S., 2015. Automatic trip and mode detection with move smarter: first results from the Dutch mobile mobility panel. Transp. Res. Procedia 11, 247-262.

Hadfield, J.D., 2010. MCMC methods for multi-response generalized linear mixed models: the MCMCglmm R package. J. Stat. Softw. 33 (2), 1-22.

Hadfield, J.D., 2016. MCMCglmm course notes, URL:http://cran.r-project.org/web/packages/MCMCglmm/vignettes/CourseNotes.pdf

Hajjem, A., Bellavance, F., Larocque, D., 2011. Mixed effects regression trees for clustered data. Stat. Probab. Lett. 81 (4), 451-459.

Hensher, D.A., Greene, W.H., 2003. The mixed logit model: the state of practice. Transportation 30 (2), $133-176$.

Kass, G.V, 1980. An exploratory technique for investigating large quantities of categorical data. Appl. Stat. 29 (2), $119-127$.

Kautz, T., Eskofier, B.M., Pasluosta, C.F., 2017. Generic performance measure for multiclass-classifiers. Pattern Recognit. 68, 111-125.

Kim, S., Yang, D., Rasouli, S., Timmermans, H.J.P., 2017. Heterogeneous hazard model of PEV users charging intervals: analysis of four year charging transactions data. Transp. Res. Part C 82, 248-260.

Kitamura, R, 2008. Longitudinal methods. In: Hensher, D.A., Button, K.J. (Eds.), Handbook of Transport Modelling, 2nd ed.. Elsevier, Oxford, pp. 133-150.

Laird, N.M., Ware, J.H., 1982. Random-effects models for longitudinal data. Biometrics 38 (4), 963-974.

Loh, W.Y., Zheng, W., 2013. Regression trees for longitudinal and multiresponse data. Ann. Appl. Stat. 7 (1), $495-522$.

Lindley, D.V., Smith, A.F., 1972. Bayes estimates for the linear model. J. Royal Stat. Soc. Ser. B 34 (1), 1-41.

Lucardie, G.L., 1994. Functional Object-Types as a Foundation of Complex Knowledge-Based Systems, Ph. D. Dissertation. Eindhoven University of Technology, Eindhoven, The Netherlands.

Mannering, F.L., Shankar, V., Bhat, C.R., 2016. Unobserved heterogeneity and the statistical analysis of highway accident data. Anal. Methods Accid. Res. 11, $1-16$.

Pitombo, C.S., Salgueiro, A.R., da Costa, A.S.G., Isler, C.A., 2015. A two-step method for mode choice estimation with socioeconomic and spatial information. Spatial Stat. 11, 45-64.

Quinlan, J.R., 1993. C4.5: Programs for Machine Learning. Morgan Kaufmann Publishers, Inc., San Mateo.

R Core Team, 2015. R: A Language and Environment for Statistical Computing. R Foundation for Statistical Computing, Vienna, Austria http://www.R-project. org/.

Rashidi, T.H., Mohammadian, A., 2011. Household travel attributes transferability analysis: Application of a hierarchical rule based approach. Transportation 38 (4), 697-714.

Rasouli, S., Timmermans, H.J.P., 2012. A multivariate adaptive regression spline emulator of travel time predicted by a complex activity-based model of travel demand. In: Mak, H.Y., Lo, H.K. (Eds.), Proceedings 17th International Conference Hong Kong Society of Transportation. Hong Kong, China, pp. 404-410.

Rasouli, S., Timmermans, H.J.P., 2013. Assessment of model uncertainty in destination and travel forecasts of models of complex spatial shopping behavior. J. Retailing Consum. Serv. 20 (2), 139-146.

Rasouli, S., Timmermans, H.J.P., 2014a. Judgments of travel experiences, activity envelopes, trip features and multi-tasking: a panel effects regression model specification. Transp. Res. Part A 63, 67-75.

Rasouli, S., Timmermans, H.J.P., 2014b. Using ensembles of decision trees to predict transport mode choice decisions: Effects on predictive success and uncertainty estimates. Eur. J. Transp. Infrastruct. Res. 14 (4), 412-424.

Rasouli, S., 2016. Uncertainty in Modelling Activity-Travel Demand in Complex Urban Systems, Ph.D. Dissertation. Eindhoven University of Technology, Eindhoven, The Netherlands.

Rasouli, S., Kim, S., Yang, D., 2018. Albatross IV: from single day to multi time horizon travel demand forecasting. Paper presented at the 97th Annual Meeting of the Transportation Research Board, Washington, D.C.

Revelt, D., Train, K., 1998. Mixed logit with repeated choices: households' choices of appliance efficiency level. Rev. Econ. Stat. 80 (4), $647-657$.

Segal, M.R, 1992. Tree-structured methods for longitudinal data. J. Am. Stat. Assoc. 87 (418), 407-418.

Sela, R.J., Simonoff, J.S., 2012. RE-EM trees: a data mining approach for longitudinal and clustered data. Mach. Learn. 86 (2), $169-207$.

Shabanpour, R., Golshani, N., Auld, J., Mohammadian, A., 2017. Dynamics of time-of-day choices in the agent-based dynamic activity planning and travel simulation (adapts) framework. In: Proceedings of 96th Annual Meeting of Transportation Research Board. Washington, D.C.

Spiegelhalter, D.J., Best, N.G., Carlin, B.P., Van Der Linde, A., 2002. Bayesian measures of model complexity and fit. J. Royal Stat. Soc. 64 (4), 583-639.

Timmermans, H.J.P., Arentze, T.A., Cenani, S., Ma, H., Pontes de Aquino, A., Sharmeen, F., Yang, D., 2010. U4IA: emerging urban futures and opportune repertoires of individual adaptation. In: Proceedings of 10th International Conference on Design \& Decision Support Systems in Architecture and Urban Planning. CD-ROM. 2010. Eindhoven, pp. 1-19.

Vij, A., Carrel, A., Walker, J.L., 2013. Incorporating the influence of latent modal preferences on travel mode choice behavior. Transp. Res. Part A 54, 164-178.

Vij, A., Shankari, K., 2015. When is big data big enough? Implications of using GPS-based surveys for travel demand analysis. Transp. Res. Part C 56, 446-462.

Wets, G., Vanhoof, K., Arentze, T.A., Timmermans, H.J.P., 2000. Identifying decision structures underlying activity patterns: an exploration of data mining algorithms. Transp. Res. Rec. (1718) 1-9.

Wooldridge, J.M., 2010. Econometric Analysis of Cross Section and Panel Data, 2nd ed. MIT Press, Cambridge, MA. 
Xianyu, J., Rasouli, S., Timmermans, H.J.P., 2017. Analysis of variability in multi-day gps imputed activity-travel diaries using multi-dimensional sequence alignment and panel effects regression models. Transportation 44 (3), 533-553.

Xiao, G., Juan, Z., Zhang, C., 2016. Detecting trip purposes from smartphone-based travel surveys with artificial neural networks and particle swarm optimization. Transp. Res. Part C 71, 447-463.

Yang, D., Timmermans, H.J.P., Grigolon, A.B., 2013. Exploring heterogeneity in travel time expenditure of aging populations in the Netherlands: results of a CHAID analysis. J. Transp. Geogr. 33, 170-179.

Yasmin, F., Morency, C., Roorda, M.J., 2017. Trend analysis of activity generation attributes over time. Transportation 44 (1), 69-89.

Zhang, H, 1998. Classification trees for multiple binary responses. J. Am. Stat. Assoc. 93 (441), 180-193. 